\title{
The Microbes We Eat: Abundance and taxonomy of microbes consumed in a day's worth of meals for three diet types (USDA recommended, vegan, and "typical American")
}

Far more attention has been paid to the microbes in our feces than the microbes in our food. Research efforts dedicated to the microbes that we eat have historically been focused on a fairly narrow range of species, namely those which cause disease and those which are thought to confer some "probiotic" health benefit. Little is known about the effects of ingested microbial communities that are present in typical American diets, and even the basic questions of which microbes, how many of them, and how much they vary from diet to diet and meal to meal, have not been answered. We characterized the microbiota of three different dietary patterns in order to estimate: the average total amount of daily microbes ingested via food and beverages, and their composition in three daily meal plans representing three different dietary patterns. The three dietary patterns analyzed were: 1) the Average American (AMERICAN): focused on convenience foods, 2) USDA recommended (USDA): emphasizing fruits and vegetables, lean meat, dairy, and whole grains, and 3) Vegan (VEGAN): excluding all animal products. Meals were prepared in a home kitchen or purchased at restaurants and blended, followed by microbial analysis including aerobic, anaerobic, yeast and mold plate counts as well as 16S rRNA PCR survey analysis. Based on plate counts, the USDA meal plan had the highest total amount of microbes at $1.3 \times 109$ CFU per day, followed by the VEGAN meal plan and the AMERICAN meal plan at 6X106 and 1.4X106 CFU per day respectively. There was no significant difference in diversity among the three dietary patterns. Individual meals clustered based on taxonomic composition independent of dietary pattern. For example, meals that were abundant in Lactic Acid Bacteria were from all three dietary patterns. Some taxonomic groups were correlated with the nutritional content of the meals. Predictive metagenome analysis using PICRUSt indicated differences in some functional KEGG categories across

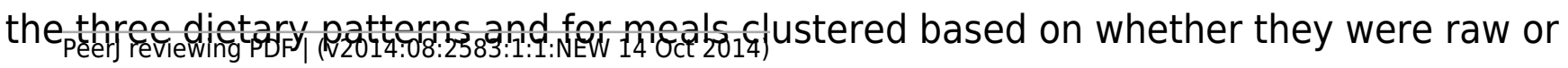


cooked. Further studies are needed to determine the impact of ingested microbes on the intestinal microbiota, the extent of variation across foods, meals and diets, and the extent to which dietary microbes may impact human health. The answers to these questions will reveal whether dietary microbes, beyond probiotics taken as supplements - i.e. , ingested with food - are important contributors to the composition, inter-individual variation, and function of our gut microbiota. 


\section{The Microbes We Eat: Abundance and taxonomy of microbes \\ 2 consumed in a day's worth of meals for three diet types (USDA \\ 3 recommended, vegan, and "typical American")}

4 Jenna M. Lang (jennomics@gmail.com). Genome Center, University of California, Davis, CA, 5 USA

6 Jonathan A. Eisen (jaeisen@ucdavis.edu). Genome Center, Evolution and Ecology, Medical

7 Microbiology and Immunology, University of California, Davis, Davis, CA, USA

8 Angela M. Zivkovic (amzivkovic@ucdavis.edu). Department of Nutrition, University of

9 California, Davis, CA, USA

101

\section{Abstract}

\section{Abstract}

Far more attention has been paid to the microbes in our feces than the microbes in our food. Research efforts dedicated to the microbes that we eat have historically been focused on a fairly narrow range of species, namely those which cause disease and those which are thought to confer some "probiotic" health benefit. Little is known about the effects of ingested microbial communities that are present in typical American diets, and even the basic questions of which microbes, how many of them, and how much they vary from diet to diet and meal to meal, have not been answered. We characterized the microbiota of three different dietary patterns in order to estimate: the average total amount of daily microbes ingested via food and beverages, and their composition in three daily meal plans representing three different dietary patterns. The three dietary patterns analyzed were: 1) the Average American (AMERICAN): focused on convenience foods, 2) USDA recommended (USDA): emphasizing fruits and vegetables, lean meat, dairy, and whole grains, and 3) Vegan (VEGAN): excluding all animal products. Meals were prepared in a home kitchen or purchased at restaurants and blended, followed by microbial analysis including aerobic, anaerobic, yeast and mold plate counts as well as $16 \mathrm{~S}$ rRNA PCR survey analysis. Based on plate counts, the USDA meal plan had the highest total amount of microbes at CFU per day, followed by the VEGAN meal plan and the AMERICAN meal plan at and CFU per day respectively. There was no significant difference in diversity among the three dietary patterns. Individual meals clustered based on taxonomic composition independent of dietary pattern. For example, meals that were abundant in Lactic Acid Bacteria were from all three dietary patterns. Some taxonomic groups were correlated with the nutritional content of the meals. Predictive metagenome analysis using PICRUSt indicated differences in some functional KEGG categories across the three dietary patterns and for meals clustered based on whether they were raw or cooked. Further studies are needed to determine the impact of ingested microbes on the intestinal microbiota, the extent of variation across foods, meals and diets, and the extent to which dietary microbes may impact human health. The answers to these questions will reveal whether dietary microbial approaches beyond probiotics taken as supplements - i.e., ingested as foods - are important contributors to the composition, interindividual variation, and function of our gut microbiota.

\section{6}

37

38

39

40

41

42

43

44

\section{Introduction}

The human gut microbiome (the total collection of microbes found in in the human gut) mediates many key biological functions and its imbalance, termed dysbiosis, is associated with a number of inflammatory and metabolic diseases from inflammatory bowel disease to asthma to obesity and insulin resistance [Error: Reference source not found] [Error: Reference source not found]. How to effectively shift the microbiome and restore balance is a key question for disease prevention and treatment. The gut microbiome is influenced by a number of factors including the nature of the initial colonization at birth (e.g., vaginal vs. C-section delivery), host genotype, age, and diet. As diet is a readily modifiable factor, it is an obvious target for interventions. Several studies have confirmed high interindividual variability in the bacterial composition of the gut microbiome in healthy individuals [Error: Reference 
source not found], [Error: Reference source not found]. Despite this high variability at the species level, enterotypes, or distinct clusters at the genus level, were described as core microbiomes that are independent of age, gender, nationality, or BMI [Error: Reference source not found]. Although the concept of enterotypes is itself controversial, diet has been shown to play a key role in determining enterotype [Error: Reference source not found-Error: Reference source not found]. Although the core microbiota within each person are stable over longer time scales (e.g. 5 years), community composition is highly dynamic on shorter time scales (e.g. 0-50 weeks) [Error: Reference source not found]. In fact, major shifts occur within 1 day of a significant dietary change [Error: Reference source not found, Error: Reference source not found]. "Blooms" in specific bacterial groups were observed in response to controlled feeding of different fermentable fibers [Error: Reference source not found]. Dietary changes affect both the structure and function of the gut microbiome in animals [Error: Reference source not found], and humans under controlled feeding conditions [Error: Reference source not found]. Rapid shifts in microbiome composition are observed in response to change from a vegetarian to an animal based diet [Error: Reference source not found].

An ecological perspective helps to delineate the complexity and multi-layered nature of the relationships between the microbiota, the human host, and both the nutritive and non-nutritive compounds we ingest [Error: Reference source not found]. The concept of the human gut microbiome as a distinct ecosystem or collection of microecosystems allows us to identify and characterize the components of the system, including its inputs and outputs. In this case, the inputs of the system include all of the various ingested compounds that can either serve as food substrates (e.g. complex sugars) or that can be metabolized by or that affect the metabolism of the microbiota (e.g. polyphenolic compounds, environmental chemicals, medications). Some of these inputs, such as probiotics have been studied extensively. It has been well documented that certain sugars such as galactooligosaccharides, fructooligosaccharides, and oligosaccharides found in milk act as prebiotics that support the establishment and growth of certain commensal microbial species [Error: Reference source not found], [Error: Reference source not found], [Error: Reference source not found], [Error: Reference source not found], [Error: Reference source not found]. Research has also documented the effects of antibiotics, and pathogens on the microbiota composition, its recovery or lack of recovery to baseline following resolution, and the various immunological and physiological effects of these perturbations [Error: Reference source not found], [Error: Reference source not found], [Error: Reference source not found][Error: Reference source not found].

Yet, little is known about the effects of ingested microorganisms on gut microbiota composition or function, and even the basic questions of which microbes, how many of them, and how much they vary from diet to diet and meal to meal, have not been answered. We do know about the microbial ecology of various specialty foods where fermentation, colonization, ripening, and/or aging are part of the preparation of these foods, for example pancetta [Error: Reference source not found] and of course cheese [Error: Reference source not found][Error: Reference source not found]. The microbial ecology of the surfaces of raw plant-derived foods such as fruits and vegetables has also been characterized [Error: Reference source not found]. There is a large base of literature on food-borne pathogens [Error: Reference source not found]. Furthermore, it is known that the microbial ecology of endemic microbes found on food surfaces can affect mechanisms by which pathogens colonize these foods [Error: Reference source not found]. A recent article showed that certain ingested microbes found in foods such as cheese and deli meats were detected in the stool of individuals who consumed them, and that furthermore they were culturable and thus survived transit through the upper intestinal tract [Error: Reference source not found]. However, the microbial ecology or microbial assemblages of different meals and diets, as well as the total number of live microorganisms ingested in these meals and diets are largely unknown. In fact, studies of the effects of diets and foods on the gut microbiota rely on dietary recalls and other dietary reporting instruments that were not designed to capture the potential variability in aspects of foods other than their basic macronutrient and micronutrient content. Specifically, current instruments for collecting individual dietary data do not capture the provenance of foods or their preparation, both of which would likely influence certain compositional aspects of the foods, especially the microbes on those foods.

We performed a preliminary study designed to generate hypotheses about the microbes we eat, and how they vary in terms of total abundance and relative composition in different meals and dietary patterns typical of American dietary intakes. We have selected to characterize the microbiota of 15 meals that exemplify the typical meals consumed as part of three different dietary patterns in order to determine the average total amount of daily microbes ingested via food and beverages and their composition in the average American adult consuming these typical foods/diets: 1) the Average American dietary pattern (AMERICAN) focused on convenience foods, 2) the USDA recommended dietary pattern (USDA) emphasizing fruits and vegetables, lean meat, dairy, and whole grains, and 3) the Vegan (VEGAN) dietary pattern, which excludes all animal products. We used DNA sequencing, plate counting, and informatics methods to characterize microbes in these meals and dietary patterns. 


\subsection{Meal preparation}

We conducted a series of experiments consisting of food preparation followed by sample preparation and microbial analysis. Food was purchased and prepared in a standard American home kitchen by the same individual using typical kitchen cleaning practices including hand washing with non-antibacterial soap between food preparation steps, washing of dishes and cooking instruments with non-antibacterial dish washing detergent, and kitchen cleanup with a combination of anti-bacterial and non-antibacterial cleaning products. Anti-bacterial products had specific anti-bacterial molecules added to them whereas "non-antibacterial" products were simple surfactant-based formulations. The goal was to simulate a typical home kitchen rather than to artificially introduce sterile practices that would be atypical of how the average American prepares their meals at home. All meals were prepared according to specific recipes (from raw ingredient preparation such as washing and chopping, to cooking and mixing).

After food preparation, meals were plated on a clean plate, weighed on a digital scale (model 157W, Escali, Minneapolis, MN), and then transferred to a blender (model 5200, Vita-Mix Corporation, Cleveland, OH) and processed until completely blended (approximately 1-3 minutes). Prepared, ready to eat foods that were purchased outside the home were simply weighed in their original packaging and then transferred to the blender. $4 \mathrm{~mL}$ aliquots of the blended meal composite were extracted from the blender, transported on dry ice and then stored at $-80^{\circ} \mathrm{C}$ until analysis. The following analyses were completed using these meal composite samples: 1) total aerobic bacterial plate counts, 2) total anaerobic bacterial plate counts, 3) yeast plate counts, 4) fungal plate counts, and 5) 16S rDNA analysis for microbial ecology.

\subsection{Diet design}

Diets were designed by a nutritional biologist to deliver the average number of Calories consumed by an average American per day. The average American woman is 63 inches in height and weighs 166 pounds, and the average American man is 69 inches in height and weighs 195 pounds with an average age of 35, National Health and Nutrition Examination Survey, which translates to a total daily Calorie intake range of 2,000 to 2,600 Calories per day respectively to maintain weight, as determined using the USDA MyPlate SuperTracker tool. Therefore an intermediate daily Calorie intake of about 2,200 Calories was chosen as the target.

Meal plans were created using the NutriHand program (Nutrihand Inc., Soraya, CA). Diet nutrient composition was calculated by the NutriHand program from reference nutrient data for individual foods using the USDA National Nutrient Database for Standard Reference. Three one-day meal plans were created to be representative of three typical dietary patterns that are consumed by Americans: 1) the Average American dietary pattern (AMERICAN), which includes meat and dairy and focuses on convenience foods, 2) the USDA recommended dietary pattern (USDA), which emphasizes fresh fruits and vegetables, lean meats, whole grains and whole grain products, and dairy, and 3) the Vegan dietary pattern (VEGAN), which excludes all animal products. The AMERICAN meal plan totaled 2268 Calories, which consisted of 35\% fat, 53\% carbohydrates of which $16.6 \mathrm{~g}$ was fiber, and 12\% protein. The USDA meal plan totaled 2260 Calories, consisting of $25 \%$ fat, $49 \%$ carbohydrates of which $45 \mathrm{~g}$ was fiber, and $27 \%$ protein. The VEGAN meal plan totaled 2264 Calories and consisted of $31 \%$ fat, $54 \%$ carbohydrates of which $52 \mathrm{~g}$ was fiber, and $15 \%$ protein.

\subsection{Microbial community analysis}

Microbial plate counts were performed by Covance Laboratories (Covance Inc., Madison, WI). Aerobic plate counts were performed according to $\underline{\mathrm{SPCM}: 7}$, anaerobic plate counts were performed according to $\underline{\mathrm{APCM}: 5}$ and the yeast and mold counts were performed according to Chapter 23 of the FDA's Bacteriological Analytical Manual. Plate counts were reported as colony forming units (CFU) per gram for each meal composite. The CFU/g values were multiplied by the total number of grams in each meal to obtain the CFU per meal, and the values for meals for each day were added to obtain the CFU per day for each dietary pattern (Table 1).

The taxonomic composition of each meal microbiome was assessed via amplification and sequencing of $16 \mathrm{~S}$ rDNA from the homogenized meals. DNA was extracted from homogenized food samples with the Power Food Microbial DNA Isolation Kit (MoBio Laboratories, Inc.) according to the manufacturer's protocol. Microbial DNA was amplified by a two-step PCR enrichment of the 16S rRNA gene (V4 region) using primers 515F and 806R, modified by addition of Illumina adaptor and barcodes sequences. All primer sequences and a detailed PCR protocol are provided in Table 2 and in a GitHub repository (https:/github.com/hollybik/protocols/blob/master/16S_rRNA_twostep_PCR.tex), respectively. Libraries were 


\section{1}

162

163

164

165

166

167

168

169

170

sequenced using an Illumina MiSeq system, generating 250bp paired-end amplicon reads. The amplicon data was multiplexed using dual barcode combinations for each sample. We used a custom script (available in a GitHub repository (https://github.com/gjospin/scripts/blob/master/Demul_trim_prep.pl), to assign each pair of reads to their respective samples when parsing the raw data. This script allows for 1 base pair difference per barcode. The paired reads were then aligned and a consensus was computed using FLASH [Error: Reference source not found] with maximum overlap of 120 and a minimum overlap of 70 (other parameters were left as default). The custom script automatically demultiplexes the data into fastq files, executes FLASH, and parses its results to reformat the sequences with appropriate naming conventions for QIIME v. 1.8.0 [Error: Reference source not found] in fasta format. The resulting consensus sequences were analyzed using the QIIME pipeline.

\subsection{Statistical Analyses and Data Visualization}

Unless otherwise noted, all statistical analyses were performed using python scripts implemented in QIIME v. 1.8.0, and all python scripts referenced here are QIIME scripts. The IPython notebook file used for all QIIME analyses is available at http://nbviewer.ipython.org/gist/jennomics/c6fe $5 \mathrm{e} 113525 \mathrm{c} 6 \mathrm{aa} 8 \mathrm{add}$. To explore the differences in overall microbial community composition across the 15 meals, both the phylogenetic weighted UniFrac distances [Error: Reference source not found] and the taxonomic Bray-Curtis dissimilarities [Error: Reference source not found] were calculated using the beta_diversity_through_plots.py script. This script also produced a principal coordinates analysis (PCoA) plot in which the Bray-Curtis dissimilarities between samples were used to visualize differences among groups of samples (see Figure 1 for this type of visualization for the three Diet Types.) To test for the significance of dietary pattern on the overall microbial community composition, we used a permutational multivariate ANOVA as implemented in the compare_categories.py script. To test for significant differences in taxonomic richness across dietary patterns, we used the non-parametric Kruskal-Wallis test [Error: Reference source not found] with the FDR (false discovery rate) correction as implemented in compare_alpha_diversity.py. To test for the significant variation in frequency of individual OTUs across dietary patterns, we used the Kruskal-Wallis test with the FDR correction as implemented in the group_significance.py script. We also used the biplot function of the make_emperor.py script to plot the family-level OTUs in PCoA space alongside each meal. To test for significant correlation between the relative abundance of a single taxonomic group and meal metadata categories (i.e. nutrient composition, whether a meal contains fermented foods, etc) at 5 taxonomic levels (phylum-genus) Pearson correlation coefficients [Error: Reference source not found] were calculated and tested for statistical significance using Stata (StataCorp. 2013. Stata Statistical Software: Release 13. College Station, TX: StataCorp LP.) Figures 2 and 3 were produced with R [Error: Reference source not found], using the phyloseq package [Error: Reference source not found].

\subsection{Metagenome Prediction with PICRUSt}

A synthetic metagenome was generated based on the observed $16 \mathrm{~S}$ rDNA sequences for each meal. To do this, the $16 \mathrm{~S}$ rDNA sequences were clustered into a collection of OTUs sharing 99\% sequence identity, using the pick_closed_reference_otus.py script. The resultant OTU table was normalized with respect to inferred 16S rRNA gene copy numbers using the normalize_by_copy_number.py script distributed with PICRUSt v. 1.0.0 [Error: Reference source not found]. The normalized OTU table was used to predict meal microbial metagenomes with PICRUSt's predict_metagenomes.py script. The final predicted metagenome is output as a .biom table, which is suitable for analysis with a tool such as STAMP [Error: Reference source not found]. We used STAMP to test for and visualize significant (predicted) functional differences in microbial communities between the three dietary patterns.

\section{Results}

\subsection{Meal Composition}

The detailed meal plans with all ingredients are shown in Table 3, food preparation descriptions (all steps prior to placing into blender and blending foods as described in methods section) are shown in Table 4, and nutrient values based on the USDA nutrient database are shown in Table 5. The AMERICAN meal plan consisted of a large Starbucks Mocha Frapuccino for breakfast, a McDonald's Big Mac, French fries, and Coca Cola for lunch, Stouffer's lasagna for dinner, and Oreo cookies for a snack. The USDA meal plan consisted of cereal with milk and raspberries for breakfast, an apple and yogurt for a morning snack, a turkey sandwich on whole wheat bread with salad (including a hard-boiled egg, grapes, parmesan cheese, and Ceasar dressing) for lunch, carrots, cottage cheese and chocolate chips for an afternoon snack, and chicken, asparagus, peas and spinach on quinoa for dinner. The VEGAN meal plan consisted of oatmeal with banana, peanut butter, and almond milk for breakfast, a protein shake (including vegetable-based protein powder, soy milk, banana and blueberries) for a morning snack, a vegetable and tofu soup 
(including soba noodles, spinach, carrots, celery and onions in vegetable broth) for lunch, an apple and almonds with tea for an afternoon snack, a Portobello mushroom burger (including Portobello mushroom, avocado, tomato, lettuce, and a whole wheat bun) with steamed broccoli for dinner, and popcorn, hazelnuts and fig bars for an evening snack.

The following meals contained fermented foods that contained live active cultures according to the package and were prepared without heat treatment: USDA meal plan snack \#1 (yogurt), lunch (parmesan cheese), and snack \#2 (cottage cheese). The following meals contained fermented foods that were cooked as part of meal preparation: VEGAN meal plan lunch (tofu), and AMERICAN meal plan lunch and dinner (cheese). Meal ingredients were purchased at local grocery stores in Saint Helena, CA, and prepared meals were purchased in restaurants in Napa, CA.

\subsection{Plate Counts}

The aerobic, anaerobic, yeast and mold plate counts are shown in Table 1. The meals ranged in total numbers of microorganisms from CFU to CFU with the aerobic and anaerobic plate counts being among the highest and the yeast and mold plate counts being among the lowest across all meals. The USDA dietary pattern had the highest total microorganisms for the day at CFU mostly due to the higher amounts of anaerobic bacteria in the morning snack ( CFU) and higher amounts of aerobic and anaerobic bacteria in the afternoon snack (5.5 X 108 and 6 X 108 CFU respectively). Not surprisingly, both of these meals contained fermented products, in the first case yogurt, and in the second case cottage cheese. The AMERICAN and VEGAN dietary patterns had 3 orders of magnitude less total microorganisms than the USDA dietary patterns, with total microorganisms of CFU and CFU respectively. Neither the AMERICAN nor the VEGAN dietary pattern meals contained fermented foods that were not heat treated as part of meal preparation. The AMERICAN lunch and dinner contained cheese that was either cooked on a grill or baked in the oven and the VEGAN lunch contained tofu, which was cooked in the vegetable broth. The USDA lunch also had the highest amounts of yeast and mold ( and CFU respectively) of all the meals, and this meal also had relatively high amounts of aerobic bacteria ( CFU). In the VEGAN dietary pattern, the morning snack had the highest amounts of aerobic and anaerobic bacteria ( and CFU respectively).

\subsection{Sequence Processing and Summary Statistics}

The number of high-quality sequences per sample (i.e., meal) ranged from 168,669 to 318,956 (see Table 6). Sequences were clustered and clusters were assigned to a taxonomic group (when possible) using the pick_open_reference_otus.py script with a 97\% similarity cutoff and the gg_13_8_otus reference taxonomy provided by the Greengenes Database Consortium (http://greengenes.secondgenome.com.) After OTU assignment, mitochondrial and chloroplast sequences were filtered out, sequences that were observed only once across all samples were removed, and sequences that were Unassigned at the Domain taxonomic level were removed (these Unassigned sequences were verified via a manual BLAST search to be chloroplast sequences.) After this filtration, the range of sequences per sample decreased to 771-244,597. All subsequent beta diversity analyses (comparisons across samples) were performed on samples that were rarefied to 771 sequences per sample.

\subsection{Taxonomic Composition and Diversity of the Different Dietary Patterns}

In terms of taxonomic alpha diversity, there was no significant difference between dietary patterns (Figure 2) (nonparametric Kruskal-Wallis test with compare_alpha_diversity.py, $p>0.6$ ). This is the case for multiple diversity metrics, including a count of the absolute number of OTUs observed, as well as the Chao1 and Shannon-Weiner (parametric and nonparametric, respectively) diversity indices, which account for the relative abundance (evenness) of the OTUs observed. We also tested for the significant variation in frequency of individual OTUs between diet types using the Kruskal-Wallis test, as implemented in the group_significance.py script. This test is appropriate for comparing independent groups, with unequal sample sizes, that may not be normally distributed. None of the OTUs were significantly different between the three diet types. The most abundant 50 OTUs (clustered at $97 \%$ similarity) belong to 25 different bacterial families, including many that are commonly found in association with plants and animals (see Figure 3).

\subsection{Factors Driving the Differences in Microbial Community Composition and Diversity of Individual Meals}

There was no effect of dietary pattern on the overall community composition within individual meals (PERMANOVA with compare_categories.py, $p=0.591$ ). There was no obvious clustering based on any potentially distinguishing feature tested, including whether the meals contained fermented foods, dairy, whether they ware raw 
or cooked, or the calculated nutritional content (see Table 5 for complete meal metadata.) However, different meals clustered together independent of dietary pattern. For example, meals that were relatively abundant in Prevotellaceae included the USDA dinner, VEGAN dinner, AMERICAN dinner, USDA breakfast, VEGAN snack 2, and VEGAN snack 3. Prevotellaceae includes organisms that tend to be very abundant in the guts of many animals, and have been associated with Inflammatory Bowel Disease in humans [Error: Reference source not found][Error: Reference source not found]. The AMERICAN snack, AMERICAN lunch, USDA snack 2 and USDA snack 1 had a high relative abundance of Streptococcaceae (Figure 4). It is difficult to know what specific features of these meals made them similar in this regard. Possible contributing factors may be provenance of ingredients and/or individual meal components such as presence of a certain fruit or vegetable.

A large amount of variation (52\%) was explained by PCo1 (i.e., the eigenvector that explains the most variation) (Figure 1), and our attempts to determine the factors driving this variation led us to look at specific taxonomic groups that may be important. We did this in two ways. First, we produced a biplot with the make_emperor.py script, showing the prevalence of bacterial families in the PCoA space defined by the weighted unifrac distance between the 15 meals (Figure 5). A cluster of 4 meals, including USDA snack 1, AMERICAN snack, AMERICAN lunch, and USDA lunch, was comprised of samples that were dominated by Lactic Acid Bacteria. These are members of the order Lactobacillales, which are commonly found in association with both food products, especially in fermented milk products [Error: Reference source not found] and human mucosal surfaces [Error: Reference source not found]. The Vegan Snack \#1 was unique in that it was dominated (70.4\%) by Xanthamonadaceae, a family containing many plant pathogens. A second cluster of 7 meals including VEGAN dinner, VEGAN breakfast, AMERICAN breakfast, AMERICAN dinner, USDA dinner, VEGAN snack 3, and USDA breakfast, was comprised of samples containing a large percentage (average $=27 \%$ ) of Thermus, a clade with many heat and dessication-resistant organisms. Second, we calculated correlations between the relative abundance of a single taxon and the PCo1 value for each meal using a simple regression (see Table 7). The bacterial family most tightly correlated with PCo1 was Streptococcaceae $(\mathrm{r}=$ 0.852).

We also asked whether the relative abundance of any particular taxonomic group was correlated with the nutritional content of the meals via pairwise Pearson's correlations. We limited this analysis to organisms that were present in all 15 meals. Due to the exploratory nature of this study, there were no specific hypotheses tested with these correlations, and therefore no corrections for multiple hypothesis testing. Some taxa frequently abundant in human microbiome studies were found to be significantly correlated with particular nutrients (Table 7). For example, members of the genus Blautia are frequently observed in human fecal samples, and in our study, the relative abundance of this genus was found to be positively correlated with the sugar content of the meals $p<0.05$ (Figure 6). We emphasize here that due to the large numbers of OTUs present in this study, corrected $p$ values were always nonsignificant. However, the goal of this small-scale study is to inform the development of future hypotheses, not test current ones. Nevertheless, this result suggests that there could be interesting relationships between the nutritional content of the foods that we eat, the microbes that associate with those foods, and our gut microbiome, not just because we are "feeding" our gut microbes, but because we are eating them as well (but, see Caveats section below.)

\section{Metagenome Prediction with PICRUSt}

Because of the vast, historical effort to make the 16S rRNA gene sequence available for hundreds of thousands of organisms, we are typically able to characterize well the taxonomic diversity of most microbial communities. One might assume that each organism present in a community has some functional role to play, and the most straightforward way to predict what that role each organism might play is to use metagenomic sequencing to interrogate the genomes of all members of the community. Unfortunately, in many cases and with current sequencing technology, the amount of microbial DNA relative to host or other environmental DNA is small enough to make metagenomic sequencing infeasible. This is the case here, where the plant and animal DNA present in the food we eat is typically much more abundant than the microbial DNA. Some exceptions may exist with respect to fermented foods, but we are equally interested the microbiota associated with a wide variety of food types.

In a case like this for which metagenomic sequencing is infeasible, another approach suggests itself. There is evidence that a correlation exists between the evolutionary relatedness of two organisms and the similarity of their genomic content [Error: Reference source not found]. This allows us to leverage the information obtained by sequencing the genome of one organism to predict the functional potential of another, even if the other genome is represented only by a $16 \mathrm{~S}$ rRNA sequence. The power of this approach is increased when very many, very closelyrelated genome sequences are available. This predictive approach has recently been implemented in the software package PICRUSt. PICRUSt uses the phylogenetic placement of a 16S rRNA sequence within a phylogeny of sequenced genomes to infer the content of the genome of the organism represented by that 16S rRNA sequence.

With PICRUSt one can calculate a metric (NSTI) that measures how closely related the average 16S rDNA sequence in an environmental sample is to an available sequenced genome. When this number is low, PICRUSt is likely to perform well in predicting the genomes of the organisms in an environmental sample (i.e., a metagenome). 
The average NSTI for our 15 meals was 0.038 , which is on par with the NSTI for the Human Microbiome Project samples (mean NSTI $=0.03 \pm 0.02$ s.d.), for which a massive effort has been made to obtain reference genome sequences [Error: Reference source not found]. This low NSTI metric suggests that PICRUSt may perform well when predicting the metaboloc potential of the microbial communities found in the meals prepared for this study. Here, we have shown the most significant KEGG functional category, for "Other N-glycan degradation" (KO 00511, $p=8.21 \mathrm{e}-3$ ), which was highest in the VEGAN dietary pattern (Figure 7). Again, this is not a significant result when a p-value correction is applied, but is nevertheless highlighted as a potential source of information when using a pilot study like this to inform future research questions. As a sanity check for the PICRUSt predictions, we compared the relative abundance of genes present in the KEGG functional category "Sporulation" between meals that were cooked were compared to those that were raw (Figure 8). As expected, because organisms that can form spores are more likely to survive the cooking process, Sporulation-associated genes are more abundant in cooked versus raw foods. All KEGG (Level 3) pathways that vary significantly between dietary patters are presented in Table 8.) These findings suggest that there are functional differences in bacterial populations associated with different foods and meals, and that these may be related not only to bacterial substrate preferences, but also techniques used in meal preparation.

\section{Summary}

In this study we estimated the total numbers and kinds of microorganisms consumed in a day by an average American adult. We analyzed meals representing three typical dietary patterns, including the Average American, USDA recommended, and Vegan diet, and found that Americans likely consume in the range of - CFU microbes per day. The USDA meal plan included two meals with non-heat treated fermented foods, which were likely responsible for the 3-fold higher total microbes in this meal plan compared to the AMERICAN and VEGAN diets. Food preparation techniques such as heating or acid treatment can kill bacteria, however, these processes affect different bacteria to different degrees. For example, spore-forming bacteria can survive heat treatment [Error: Reference source not found] (also see Figure 8). Once inside the gastrointestinal tract, the low $\mathrm{pH}$ of the stomach, as well as bile salts also kill some bacteria, but not those that are acid and/or bile salt resistant. It is unknown what proportion of the microbes we eat make it through the hostile environment of the gastrointestinal tract. However, a recent study showed that food microbes consumed as part of fermented foods such as cheese did appear in the stool and were culturable [Error: Reference source not found].

We also used PICRUSt to predict the functional potential of the microbiota associated with each meal in this study. Of course, this is not a perfect substitute for metagenomic sequencing or experimental studies, but it does allow one to develop some initial hypotheses related to the function of a microbial community. For example, between diet types, the most significant difference in KEGG functional categories was for "other N-glycan degradation." This function was over-represented in the Vegan diet, which is perhaps not surprising given that cellulose is a glycan, and the Vegan diet is significantly higher in cellulose than the others. This suggests that when one consumes a diet that is high in cellulose, one also consumes a population of microbes that is well equipped to digest cellulose.

\subsection{Caveats}

It is important to point out some caveats with regard to this study. First, the scale of this study was limited. Our objective with this preliminary study was to explore the possiblity that the microbes in our food may be meaningful contributors to the ecosystem of our gut microbiota. The current paradigm is that the harsh conditions of the human gastrointestinal tract (i.e. high acidity in the stomach, presence of bile acids and digestive enzymes in the small intestine) preclude most microbes present in and on food from playing significant roles in the gastrointestinal microbial ecosystem because they do not survive intact. Yet recent reports show that there are microbial blooms within 24 hours of large shifts in the diet [Error: Reference source not found][Error: Reference source not found], attributed to changes in the available fermentable substrate, which in turn promoted the growth of specific bacteria already present in the gut. The possiblity remains that microbes present on the food itself contributed at least in part to these observed transient blooms or shifts. Very little is known about how different food matrices may promote the survival of food bacteria despite their lack of acid and bile acid resistance in vitro. Transient shifts in gut microbiome composition caused by dietary factors may be unimportant when the gut microbiome rebounds to its initial state. However, it is possible that under certain conditions, such perturbations could lead to functional and long-lasting changes. The goal of this study was not to explore the explicit effects of ingesting food microbes on changes in the gut microbiota but simply to provide preliminary data on the composition and numbers of bacteria in typical American dietary patterns.

Second, the study did not aim to be exhaustive in its exploration of diets. We did not aim to produce statistically significant differences in microbial composition and quantity in replicates across multiple days of a particular dietary pattern. Instead, the aim was to generate hypotheses about dietary microbes and their variation across meals and diets 
that can now be followed up with more rigorous studies. Because the purpose of this study was to generate hypotheses rather than test specific hypotheses, multiple testing corrections were not applied in our statistical analyses.

Third, the microbial counts reported here are rough estimates of the total amount of microbes consumed in a day by an average American eating meals described here. It is important to note that inherent to the plate count techniques used, not every microbe will grow under these culture conditions, and the plate counts are only estimates.

\subsection{Future Directions}

It is possible that part of the high variation in gut microbiota composition observed among individuals is due to the specific and complex differences in diet beyond the nutrient composition that can be estimated from dietary records and recalls. This study begs the question: do the microbes we eat as part of our normal daily diets contribute to the composition and function of our gut microbiota? There are many questions that remain to be answered. Under what circumstances do microbes consumed as part of meals remain in the gastrointestinal tract transiently versus persistently following a meal? Do the microbes we eat affect the function of the resident gut microbiota, even if they do not affect its composition, as has been suggested by some yogurt feeding studies [Error: Reference source not found]? How do different cooking and preparation methods affect the microbial composition of meals and the survival characteristics of individual microbes through the gastrointestinal tract? How do specific factors such as length of transport or provenance of individual ingredients (e.g. imported vs. domestic), packaging materials, and handling of ingredients in homes alter the microbial composition of foods? The findings of this study suggest that the microbes we eat as part of normal diets vary in absolute abundance, community composition, and functional potential. This variation depends on the specific ingredients in the meals, whether and how the foods are prepared and processed, and other potential factors, not explored here, including the provenance of ingredients. The significance of this variation on the gut microbiota composition and function, and its impact on human health remains to be elucidated. In addition, much as certain gut microbes can transform and modify dietary constituents and nutrients such as polyphenolic compounds and vitamins in the gut [Error: Reference source not found], it is possible that food microbes similarly modify nutritive molecules. Future studies need to explore these questions in rigorous study designs aimed at addressing key questions about the composition and content of food microbes and how these vary across diets and meals, and their impacts on the short term and long term composition and function of the gut microbiota.

All data underlying the results presented here can be found on Figshare (http://figshare.com/account/projects/2225). 


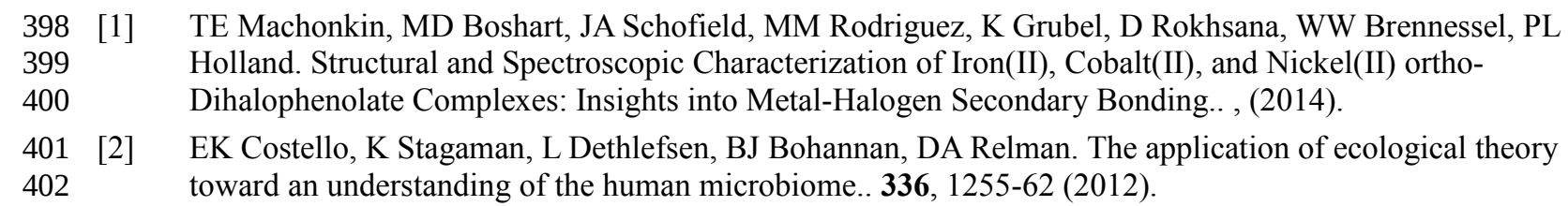

[4] E. K. Costello, C. L. Lauber, M. Hamady, N. Fierer, J. I. Gordon, R. Knight. Bacterial Community Variation in Human Body Habitats Across Space and Time. Science 326, 1694-1697 (2009). Link

[5] Manimozhiyan Arumugam, Jeroen Raes, Eric Pelletier, Denis Le Paslier, Takuji Yamada, Daniel R. Mende, Gabriel R. Fernandes, Julien Tap, Thomas Bruls, Jean-Michel Batto, Marcelo Bertalan, Natalia Borruel, Francesc Casellas, Leyden Fernandez, Laurent Gautier, Torben Hansen, Masahira Hattori, Tetsuya Hayashi, Michiel Kleerebezem, Ken Kurokawa, Marion Leclerc, Florence Levenez, Chaysavanh Manichanh, H. BjNielsen, Trine Nielsen, Nicolas Pons, Julie Poulain, Junjie Qin, Thomas Sicheritz-Ponten, Sebastian Tims, David Torrents, Edgardo Ugarte, Erwin G. Zoetendal, Jun Wang, Francisco Guarner, Oluf Pedersen, Willem M. de Vos, SBrunak, Joel Doré, María Antolín, François Artiguenave, Hervé M. Blottiere, Mathieu Almeida, Christian Brechot, Carlos Cara, Christian Chervaux, Antonella Cultrone, Christine Delorme, Gérard Denariaz, Rozenn Dervyn, Konrad U. Foerstner, Carsten Friss, Maarten van de Guchte, Eric Guedon, Florence Haimet, Wolfgang Huber, Johan van Hylckama-Vlieg, Alexandre Jamet, Catherine Juste, Ghalia Kaci, Jan Knol, Omar Lakhdari, Severine Layec, Karine Le Roux, Emmanuelle Maguin, Alexandre Mérieux, Raquel Melo Minardi, Christine M'rini, Jean Muller, Raish Oozeer, Julian Parkhill, Pierre Renault, Maria Rescigno, Nicolas Sanchez, Shinichi Sunagawa, Antonio Torrejon, Keith Turner, Gaetana Vandemeulebrouck, Encarna Varela, Yohanan Winogradsky, Georg Zeller, Jean Weissenbach, S. Dusko Ehrlich, Peer Bork. Enterotypes of the human gut microbiome. Nature 473, 174-180 (2011). Link

[6] G. D. Wu, J. Chen, C. Hoffmann, K. Bittinger, Y.-Y. Chen, S. A. Keilbaugh, M. Bewtra, D. Knights, W. A. Walters, R. Knight, R. Sinha, E. Gilroy, K. Gupta, R. Baldassano, L. Nessel, H. Li, F. D. Bushman, J. D. Lewis. Linking Long-Term Dietary Patterns with Gut Microbial Enterotypes. Science 334, 105-108 (2011). Link

[7] C. De Filippo, D. Cavalieri, M. Di Paola, M. Ramazzotti, J. B. Poullet, S. Massart, S. Collini, G. Pieraccini, P. Lionetti. Impact of diet in shaping gut microbiota revealed by a comparative study in children from Europe and rural Africa. Proceedings of the National Academy of Sciences 107, 14691-14696 (2010). Link

[8] B. D. Muegge, J. Kuczynski, D. Knights, J. C. Clemente, A. Gonzalez, L. Fontana, B. Henrissat, R. Knight, J. I. Gordon. Diet Drives Convergence in Gut Microbiome Functions Across Mammalian Phylogeny and Within Humans. Science 332, 970-974 (2011). Link

[9] J. J. Faith, J. L. Guruge, M. Charbonneau, S. Subramanian, H. Seedorf, A. L. Goodman, J. C. Clemente, R. Knight, A. C. Heath, R. L. Leibel, M. Rosenbaum, J. I. Gordon. The Long-Term Stability of the Human Gut Microbiota. Science 341, 1237439-1237439 (2013). Link

[10] P. J. Turnbaugh, V. K. Ridaura, J. J. Faith, F. E. Rey, R. Knight, J. I. Gordon. The Effect of Diet on the Human Gut Microbiome: A Metagenomic Analysis in Humanized Gnotobiotic Mice. Science Translational Medicine 1, 6ra14-6ra14 (2009). Link

[11] Alan W Walker, Jennifer Ince, Sylvia H Duncan, Lucy M Webster, Grietje Holtrop, Xiaolei Ze, David Brown, Mark D Stares, Paul Scott, Aurore Bergerat, Petra Louis, Freda McIntosh, Alexandra M Johnstone, Gerald E Lobley, Julian Parkhill, Harry J Flint. Dominant and diet-responsive groups of bacteria within the human colonic microbiota. The ISME Journal 5, 220-230 (2011). Link

[12] Marie A. Hildebrandt, Christian Hoffmann, Scott A. SherrilltextendashMix, Sue A. Keilbaugh, Micah Hamady, Ying $\mid$ textendashYu Chen, Rob Knight, Rexford S. Ahima, Frederic Bushman, Gary D. Wu. High-Fat Diet Determines the Composition of the Murine Gut Microbiome Independently of Obesity. Gastroenterology 137, 1716-1724.e2 (2009). Link

[13] Lawrence A. David, Corinne F. Maurice, Rachel N. Carmody, David B. Gootenberg, Julie E. Button, Benjamin E. Wolfe, Alisha V. Ling, A. Sloan Devlin, Yug Varma, Michael A. Fischbach, Sudha B. Biddinger, Rachel J. Dutton, Peter J. Turnbaugh. Diet rapidly and reproducibly alters the human gut microbiome. Nature 505, 559563 (2013). Link

[14] Vrese M de, J Schrezenmeir. Probiotics, prebiotics, and synbiotics.. 111, 1-66 (2008).

[15] M Roberfroid. Prebiotics: the concept revisited.. 137, 830S-7S (2007). 
[16] JB German, SL Freeman, CB Lebrilla, DA Mills. Human milk oligosaccharides: evolution, structures and bioselectivity as substrates for intestinal bacteria.. 62, 205-18; discussion 218-22 (2008).

[17] AM Zivkovic, D Barile. Bovine milk as a source of functional oligosaccharides for improving human health.. 2, 284-9 (2011).

[18] C Manichanh, J Reeder, P Gibert, E Varela, M Llopis, M Antolin, R Guigo, R Knight, F Guarner. Reshaping the gut microbiome with bacterial transplantation and antibiotic intake.. 20, 1411-9 (2010).

[19] C Ubeda, EG Pamer. Antibiotics, microbiota, and immune defense.. 33, 459-66 (2012).

[20] J Bien, V Palagani, P Bozko. The intestinal microbiota dysbiosis and Clostridium difficile infection: is there a relationship with inflammatory bowel disease?. 6, 53-68 (2013).

[21] L. Dethlefsen, D. A. Relman. Incomplete recovery and individualized responses of the human distal gut microbiota to repeated antibiotic perturbation. Proceedings of the National Academy of Sciences 108, 45544561 (2010). Link

[22] Matteo Busconi, Carla Zacconi, Gianluigi Scolari. Bacterial ecology of PDO Coppa and Pancetta Piacentina at the end of ripening and after MAP storage of sliced product. International Journal of Food Microbiology 172, 13-20 (2014). Link

[23] M. Gatti, J. De Dea Lindner, A. De Lorentiis, B. Bottari, M. Santarelli, V. Bernini, E. Neviani. Dynamics of Whole and Lysed Bacterial Cells during Parmigiano-Reggiano Cheese Production and Ripening. Applied and Environmental Microbiology 74, 6161-6167 (2008). Link

[24] Julie E. Button, Rachel J. Dutton. Cheese microbes. Current Biology 22, R587-R589 (2012). Link

[25] JW Leff, N Fierer. Bacterial communities associated with the surfaces of fresh fruits and vegetables.. 8, e59310 (2013).

[26] Nejma Aboutaleb, Edward J. Kuijper, Jaap T. van Dissel. Emerging infectious colitis. Current Opinion in Gastroenterology 30, 106-115 (2014). Link

[27] Faith J Critzer, Michael P Doyle. Microbial ecology of foodborne pathogens associated with produce. Current Opinion in Biotechnology 21, 125-130 (2010). Link

[28] T Magoč, SL Salzberg. FLASH: fast length adjustment of short reads to improve genome assemblies.. 27, 2957-63 (2011).

[29] JG Caporaso, J Kuczynski, J Stombaugh, K Bittinger, FD Bushman, EK Costello, N Fierer, AG Peña, JK Goodrich, JI Gordon, GA Huttley, ST Kelley, D Knights, JE Koenig, RE Ley, CA Lozupone, D McDonald, BD Muegge, M Pirrung, J Reeder, JR Sevinsky, PJ Turnbaugh, WA Walters, J Widmann, T Yatsunenko, J Zaneveld, R Knight. QIIME allows analysis of high-throughput community sequencing data.. 7, 335-6 (2010).

[30] C Lozupone, ME Lladser, D Knights, J Stombaugh, R Knight. UniFrac: an effective distance metric for microbial community comparison.. 5, 169-72 (2011).

[31] J. Roger Bray, J. T. Curtis. An Ordination of the Upland Forest Communities of Southern Wisconsin. Ecological Monographs 27, 325 (1957). Link

[32] William H. Kruskal, W. Allen Wallis. Use of Ranks in One-Criterion Variance Analysis. Journal of the American Statistical Association 47, 583-621 (1952). Link

[33] Karl Pearson. Note on Regression and Inheritance in the Case of Two Parents. Proceedings of the Royal Society of London (1854-1905) 58, 240-242 (1895). Link

[34] R-project. R: A Language and Environment for Statistical Computing. (2014). Link

[35] PJ McMurdie, S Holmes. phyloseq: an R package for reproducible interactive analysis and graphics of microbiome census data.. PLoS One 8, e61217 (2013).

[36] MG Langille, J Zaneveld, JG Caporaso, D McDonald, D Knights, JA Reyes, JC Clemente, DE Burkepile, Thurber RL Vega, R Knight, RG Beiko, C Huttenhower. Predictive functional profiling of microbial communities using 16S rRNA marker gene sequences.. 31, 814-21 (2013).

[37] DH Parks, GW Tyson, P Hugenholtz, RG Beiko. STAMP: Statistical analysis of taxonomic and functional profiles.. , (2014).

[38] G Henderson, F Cox, S Kittelmann, VH Miri, M Zethof, SJ Noel, GC Waghorn, PH Janssen. Effect of DNA extraction methods and sampling techniques on the apparent structure of cow and sheep rumen microbial communities.. 8, e74787 (2013).

[39] GD Wu, FD Bushmanc, JD Lewis. Diet, the human gut microbiota, and IBD.. 24, 117-20 (2013).

[40] Amarela Terzic-Vidojevic, Sanja Mihajlovic, Gordana Uzelac, Katarina Veljovic, Maja Tolinacki, Milica 
Nikolic, Ljubisa Topisirovic, Milan Kojic. Characterization of lactic acid bacteria isolated from artisanal Travnik young cheeses sweet creams and sweet kajmaks over four seasons. Food Microbiology 39, 27-38 (2014). Link

[41] Valeria Rizzello, Irene Bonaccorsi, Maria Luisa Dongarrà, Lisbeth Nielsen Fink, Guido Ferlazzo. Role of Natural Killer and Dendritic Cell Crosstalk in Immunomodulation by Commensal Bacteria Probiotics. Journal of Biomedicine and Biotechnology 2011, 1-10 (2011). Link

[42] Adam C Martiny, Kathleen Treseder, Gordon Pusch. Phylogenetic conservatism of functional traits in microorganisms. The ISME Journal 7, 830-838 (2012). Link

[43] LM Proctor. The Human Microbiome Project in 2011 and beyond.. 10, 287-91 (2011).

[44] S.C. Stringer, M.D. Webb, M.W. Peck. Lag time variability in individual spores of Clostridium botulinum. Food Microbiology 28, 228-235 (2011). Link

[45] Alan W Walker, Jennifer Ince, Sylvia H Duncan, Lucy M Webster, Grietje Holtrop, Xiaolei Ze, David Brown, Mark D Stares, Paul Scott, Aurore Bergerat, Petra Louis, Freda McIntosh, Alexandra M Johnstone, Gerald E Lobley, Julian Parkhill, Harry J Flint. Dominant and diet-responsive groups of bacteria within the human colonic microbiota. The ISME Journal 5, 220-230 (2010). Link

[46] N. P. McNulty, T. Yatsunenko, A. Hsiao, J. J. Faith, B. D. Muegge, A. L. Goodman, B. Henrissat, R. Oozeer, S. Cools-Portier, G. Gobert, C. Chervaux, D. Knights, C. A. Lozupone, R. Knight, A. E. Duncan, J. R. Bain, M. J. Muehlbauer, C. B. Newgard, A. C. Heath, J. I. Gordon. The Impact of a Consortium of Fermented Milk Strains on the Gut Microbiome of Gnotobiotic Mice and Monozygotic Twins. Science Translational Medicine 3, 106ra106-106ra106 (2011). Link

[47] Kieran M. Tuohy, Lorenza Conterno, Mattia Gasperotti, Roberto Viola. Up-regulating the Human Intestinal Microbiome Using Whole Plant Foods Polyphenols, and/or Fiber. Journal of Agricultural and Food Chemistry 60, 8776-8782 (2012). Link 
Figure 1 (on next page)

Principle Coordinates Analysis plot

Principle Coordinates Analysis (PCOA) based on Bray-Curtis dissimilarities of microbial communities found in the 15 meals, color-coded according to the dietary patterns they represent. Axes are scaled to the amount of variation explained. 


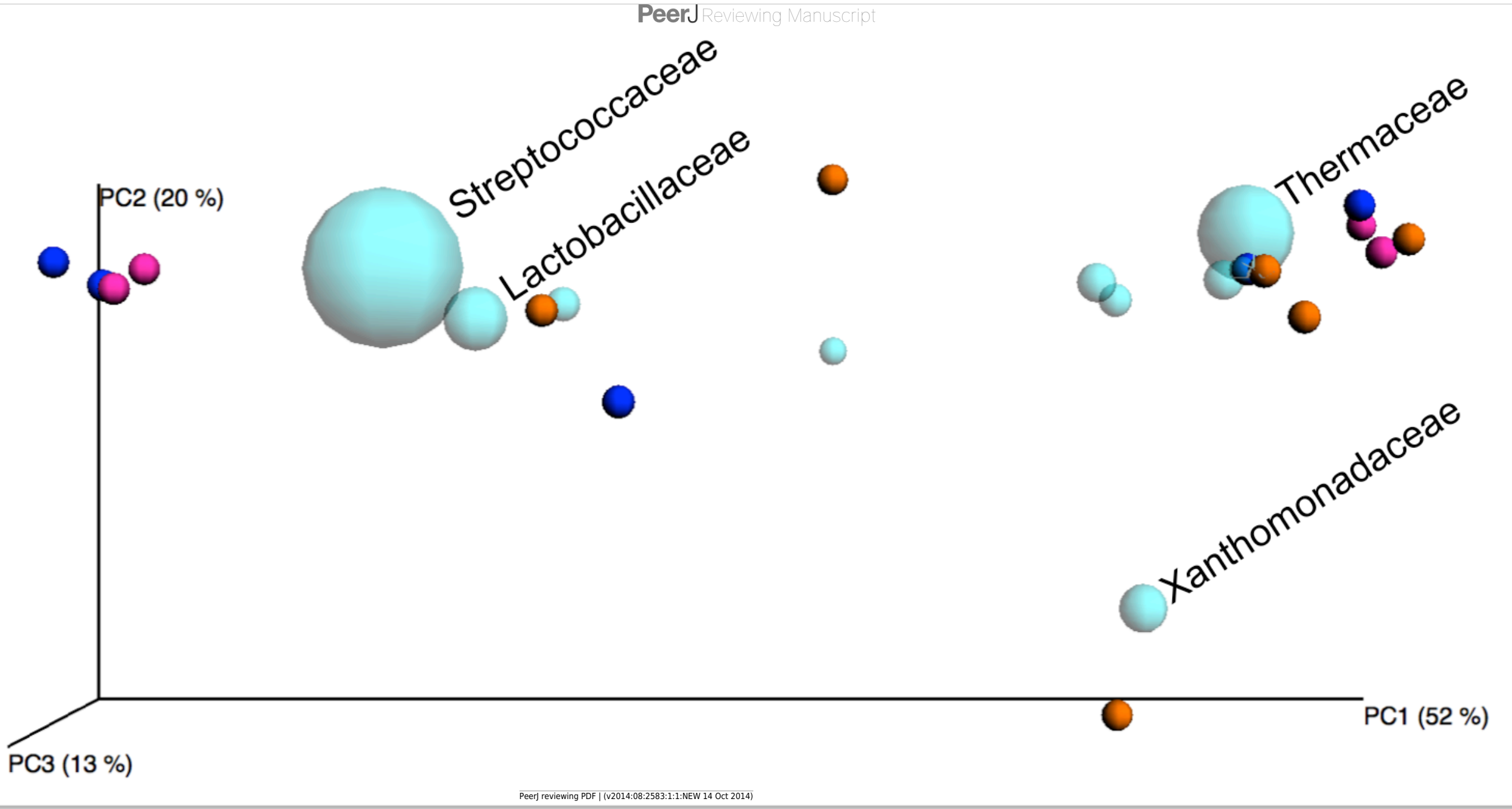


Figure 2

Alpha diversity measures for the three diet types.

While some individual meals had higher alpha diversity (defined either by the number of OTUs observed or by the Chaol and Shannon diversity measures) than others, there was no significant difference in diversity between the different dietary patterns (AMERICAN, USDA, and VEGAN).

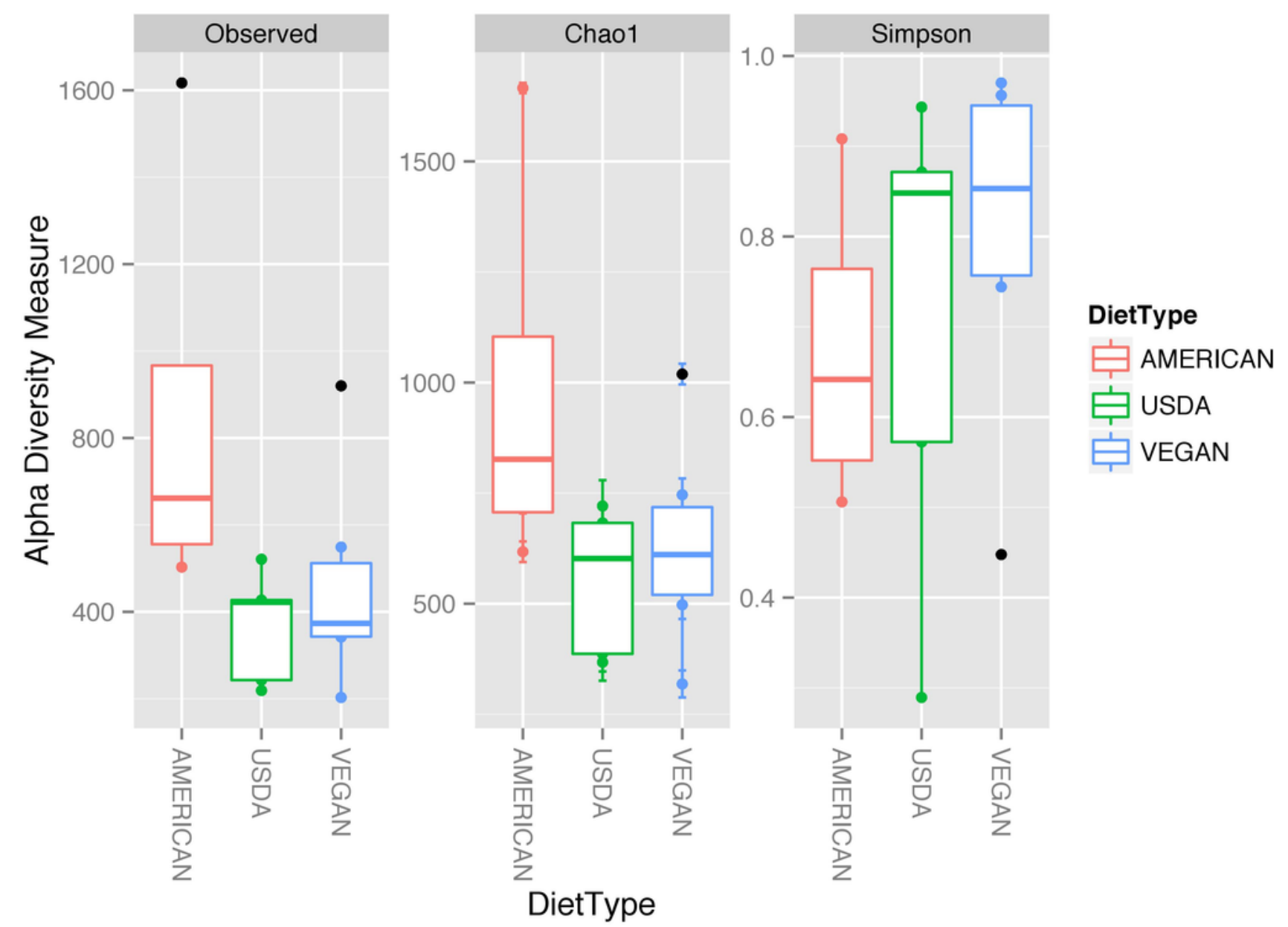




\section{Figure 3}

The cumulative relative abundance of Families representing the 50 most abundant OTUs.

The 50 most abundant OTUs in this study (clustered at $97 \%$ similarity) belong to 25 different bacterial families, including many that are commonly found in association with plants and animals. None of them vary significantly with respect to diet type.

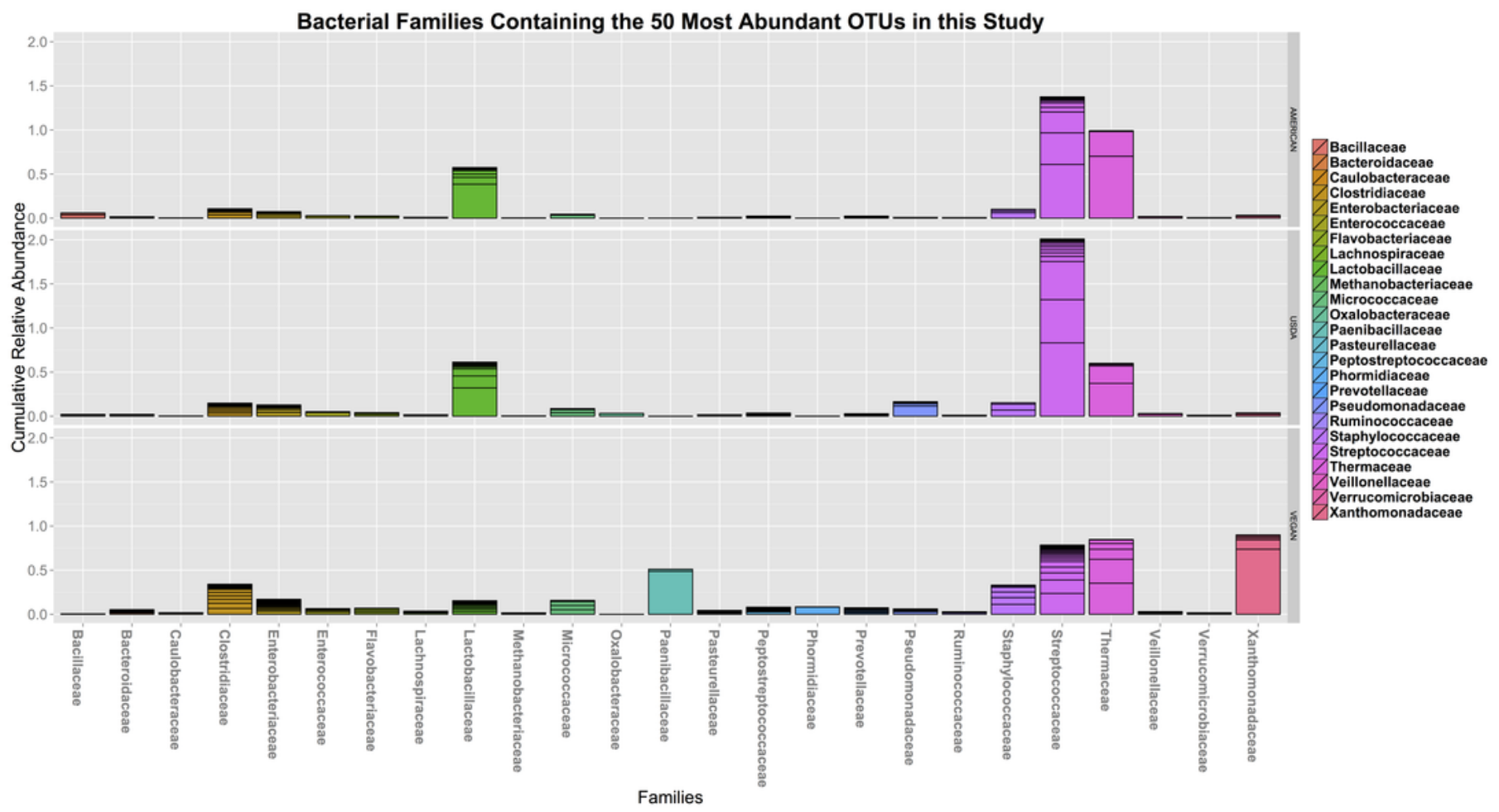




\section{Figure 4}

Heatmap of taxa abundance in each meal.

Heatmap showing relative abundance of bacterial families of individual meals. Similarities between meals are not necessarily part of the same dietary pattern. Hierarchical clustering is based on Ward clustering of the Pearson correlation coefficients, with sample by sample normalization performed using the median. 
- USDA

- AMERICAN

- VEGAN
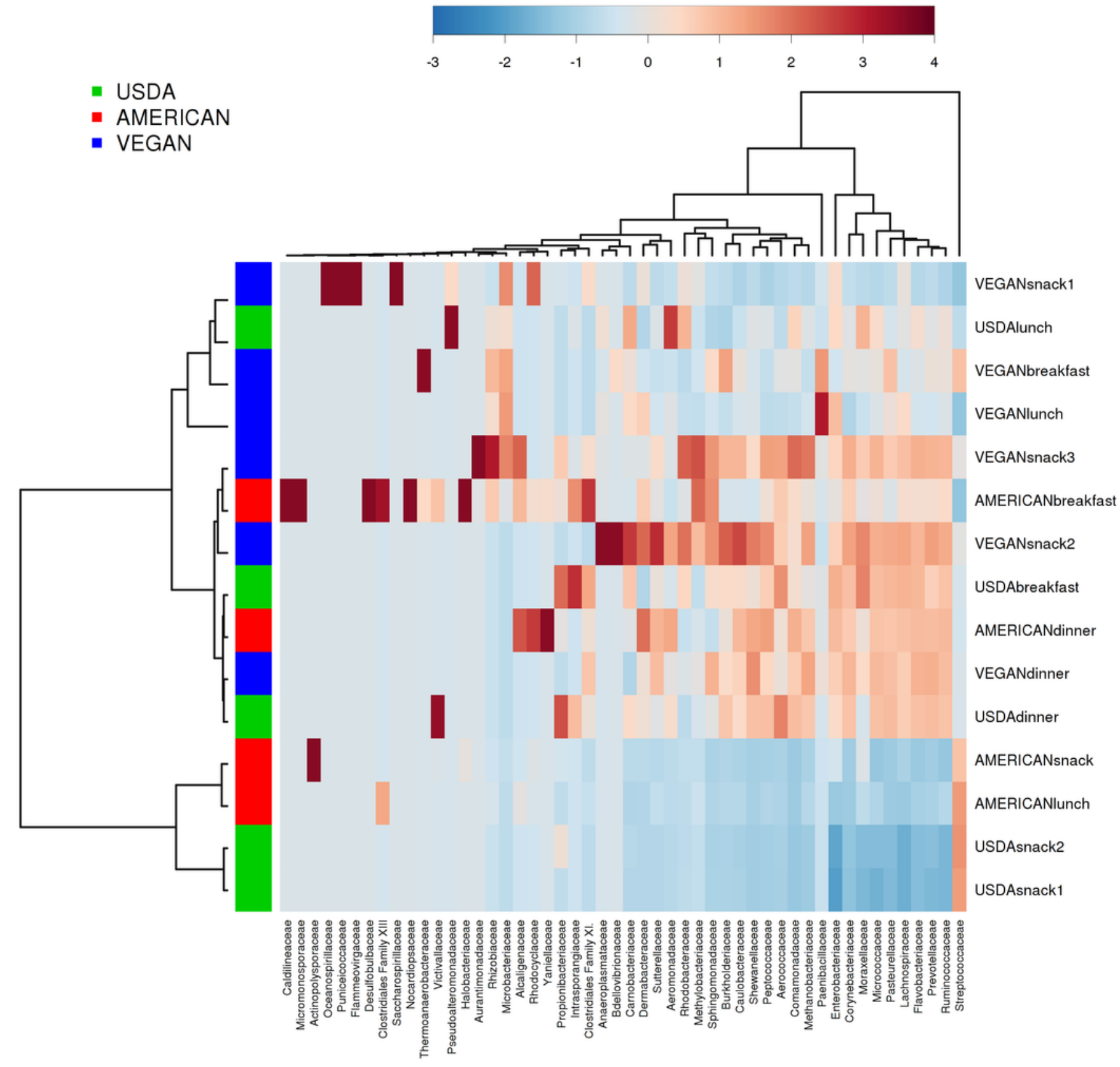
Figure 5 (on next page)

Biplot of taxa in sample PCoA space.

Bacterial families (light blue spheres) are displayed in a PCoA biplot based on weighted Unifrac distances between the 15 meals. The size of the spheres representing taxa is correlated with the relative abundance of the labeled organism. In the interest of readability, only the bacterial families discussed in the text are labeled. Axes are scaled to amount of variation explained. 
Figure 6

Correlation of Blautia abundance with sugar content in meals.

Scatterplot with simple regression line of the relative abundance of Blautia versus grams of sugar in each sample (i.e., meal). Pearson's $r=0.56$

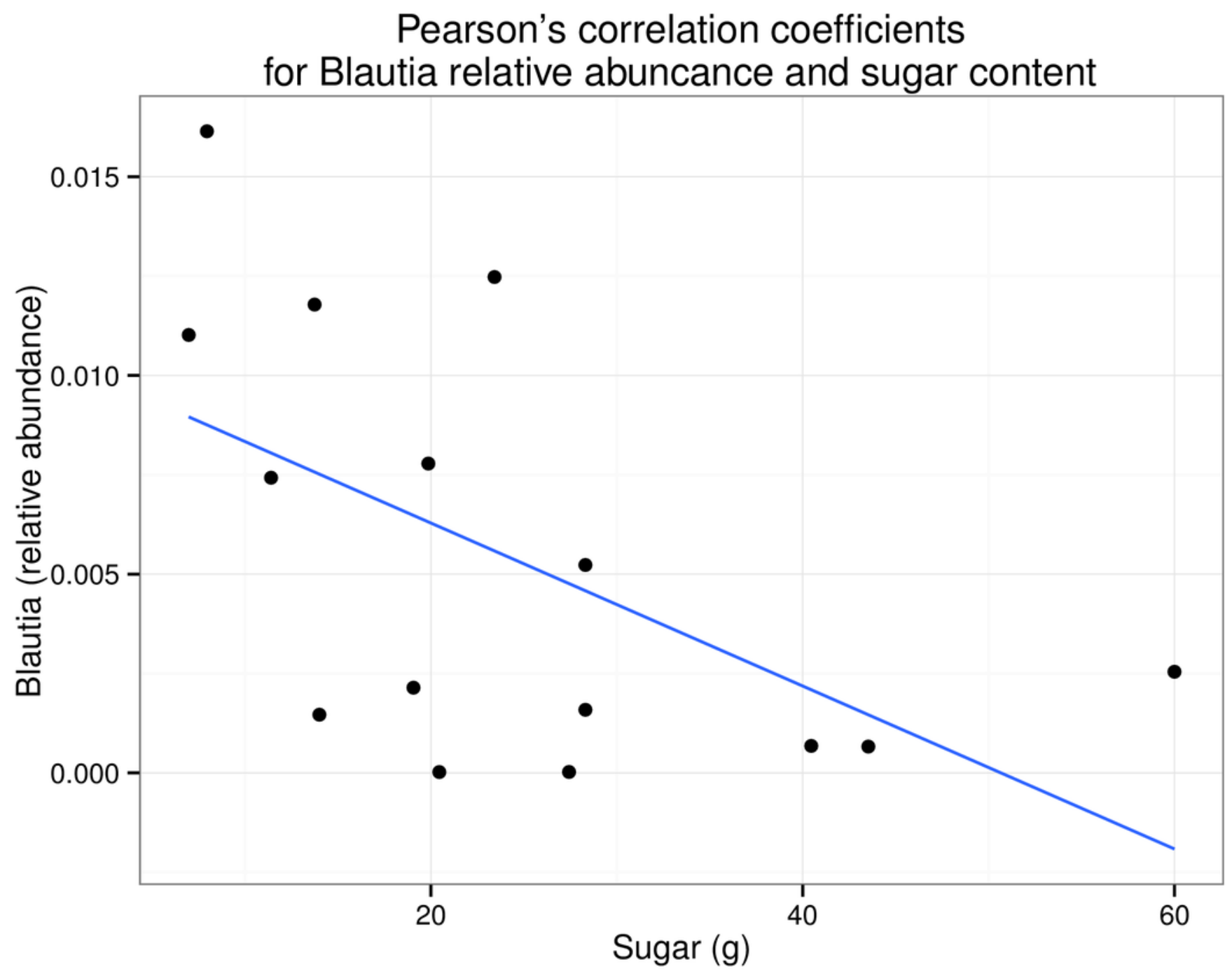




\section{Figure 7}

PICRUSt metagenome prediction suggests higher abundance of genes in the "Other glycan degradation" KEGG pathway in the VEGAN diet.

Metagenome prediction with PICRUSt reveals functional categories that differ significantly between the AMERICAN, USDA, and VEGAN diet types. The abundance of genes annotated in the "Other glycan degradation" (KO00155) pathway are significantly higher in the VEGAN diet $(p=8.21 \mathrm{e}-3)$. Due to the exploratory nature of this data set corrections for multiple testing were not applied. 


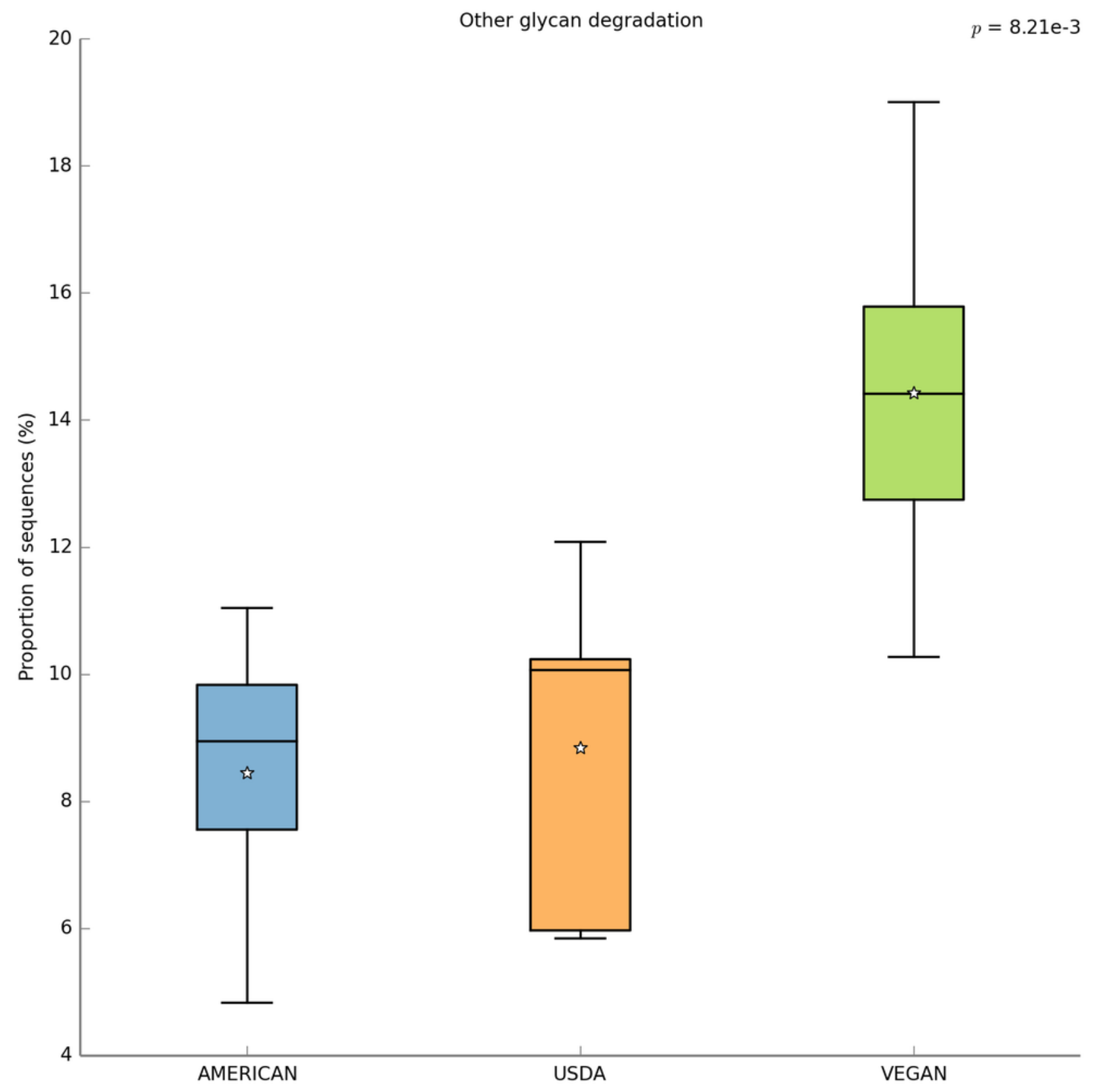




\section{Figure 8}

PICRUSt metagenome prediction suggests higher abundance of genes in the "Sporulation" KEGG pathway in cooked meals.

Metagenome prediction with PICRUSt reveals functional categories that differ significantly between the cooked and raw meal types. The abundance of genes annotated in the "Sporulation" pathway are significantly higher in the cooked meals $(p=0.039)$. Due to the exploratory nature of this data set corrections for multiple testing were not applied. 


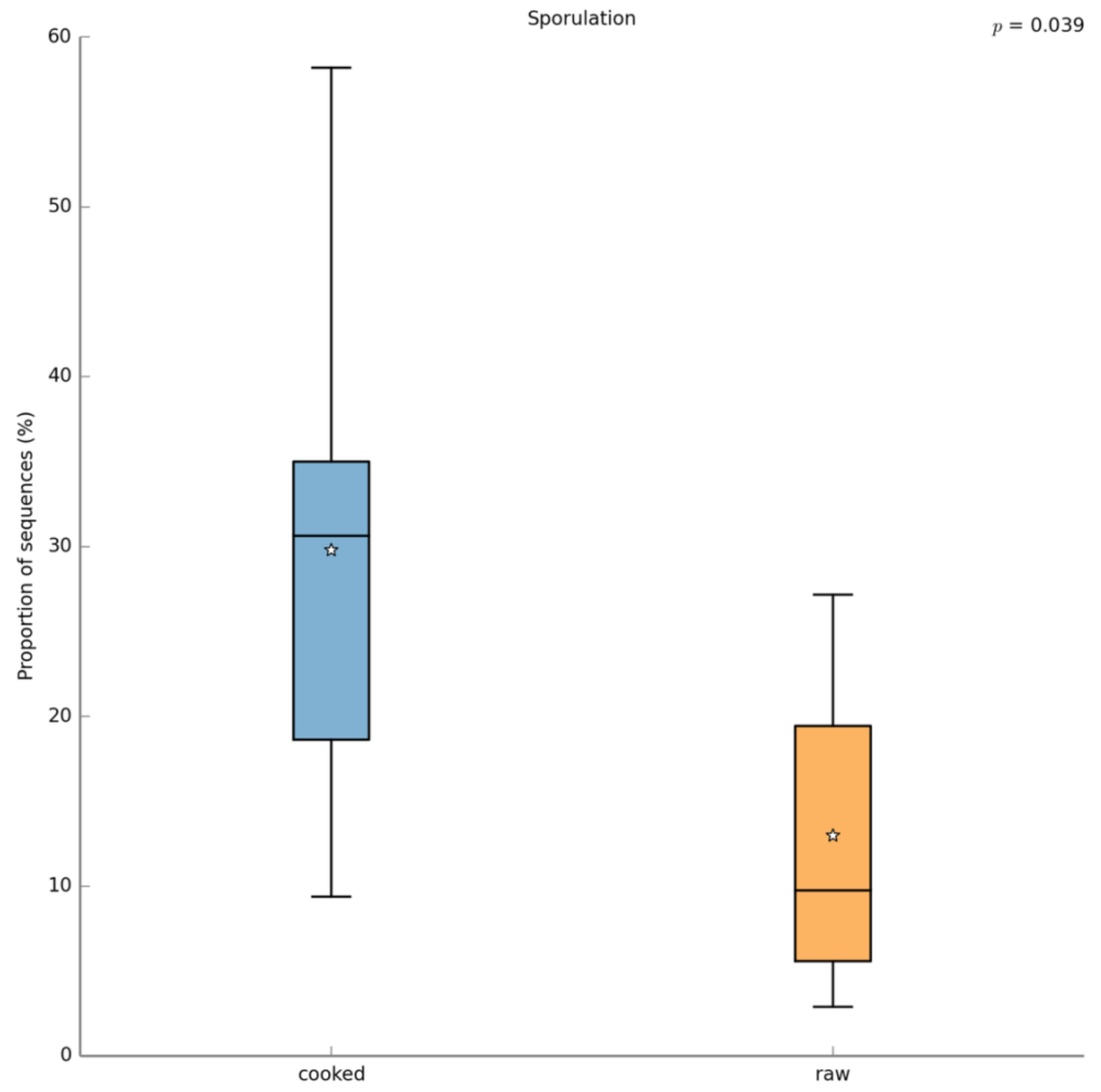


Table $\mathbf{1}$ (on next page)

Aerobic and anaerobic microbial plate counts.

Bacterial (aerobic and anaerobic), yeast, and mold plate counts were performed by Covance Laboratories (Covance Inc., Madison, WI). Plate counts are reported as colony forming units (CFU) per gram for each meal. 


\begin{tabular}{|c|c|c|c|c|c|c|}
\hline $\begin{array}{l}\text { Dietary } \\
\text { Pattern } \\
\text { Average }\end{array}$ & Meal & $\begin{array}{l}\text { Aerobic } \\
\text { Plate Count }\end{array}$ & $\begin{array}{l}\text { Anaerobic } \\
\text { Plate Count }\end{array}$ & Yeast Count & Mold Count & $\begin{array}{l}\text { Total } \\
\text { Microorganisms }\end{array}$ \\
\hline \multirow[t]{5}{*}{ American } & Breakfast & $2.15 E+05$ & $2.26 \mathrm{E}+05$ & $5.66 \mathrm{E}+02$ & $5.66 \mathrm{E}+03$ & $4.48 E+05$ \\
\hline & Lunch & $2.23 E+05$ & $1.31 \mathrm{E}+04$ & $1.31 \mathrm{E}+03$ & $1.31 \mathrm{E}+03$ & $2.38 \mathrm{E}+05$ \\
\hline & Snack & $1.87 \mathrm{E}+04$ & $2.34 \mathrm{E}+03$ & $2.34 \mathrm{E}+02$ & $2.34 \mathrm{E}+02$ & $2.15 E+04$ \\
\hline & Dinner & $1.47 \mathrm{E}+05$ & $5.35 E+05$ & $7.75 \mathrm{E}+02$ & $7.75 E+02$ & $6.84 \mathrm{E}+05$ \\
\hline & Total & $6.04 \mathrm{E}+05$ & 7.77E+05 & $2.88 \mathrm{E}+03$ & $7.98 \mathrm{E}+03$ & $1.39 E+06$ \\
\hline \multicolumn{7}{|l|}{ USDA } \\
\hline \multirow[t]{6}{*}{ Recommended } & Breakfast & $1.14 \mathrm{E}+04$ & $5.72 E+02$ & $4.29 E+04$ & $1.49 \mathrm{E}+06$ & $1.54 \mathrm{E}+06$ \\
\hline & Snack \#1 & $2.11 \mathrm{E}+05$ & $5.42 E+07$ & $5.42 \mathrm{E}+02$ & $1.19 \mathrm{E}+05$ & $5.45 E+07$ \\
\hline & Lunch & $3.25 E+07$ & $2.26 \mathrm{E}+06$ & $1.06 \mathrm{E}+06$ & $2.55 \mathrm{E}+06$ & $3.84 \mathrm{E}+07$ \\
\hline & Snack \#2 & $5.54 \mathrm{E}+08$ & $6.09 E+08$ & $3.32 \mathrm{E}+04$ & $1.39 \mathrm{E}+04$ & $1.16 \mathrm{E}+09$ \\
\hline & Dinner & $3.49 E+05$ & $5.81 E+04$ & $9.69 \mathrm{E}+02$ & $9.69 \mathrm{E}+03$ & $4.17 E+05$ \\
\hline & Total & $5.87 E+08$ & $6.66 \mathrm{E}+08$ & $1.14 \mathrm{E}+06$ & $4.18 \mathrm{E}+06$ & $1.26 \mathrm{E}+09$ \\
\hline \multirow[t]{7}{*}{ Vegan } & Breakfast & $3.38 \mathrm{E}+04$ & $1.99 E+04$ & $3.98 \mathrm{E}+02$ & $9.95 \mathrm{E}+03$ & $6.41 E+04$ \\
\hline & Snack \#1 & $1.97 \mathrm{E}+06$ & $1.67 E+06$ & $5.41 \mathrm{E}+05$ & $4.92 E+05$ & $4.67 E+06$ \\
\hline & Lunch & $1.22 \mathrm{E}+05$ & $2.34 \mathrm{E}+04$ & $9.35 \mathrm{E}+02$ & $9.35 \mathrm{E}+02$ & $1.47 \mathrm{E}+05$ \\
\hline & Snack \#2 & $9.81 E+04$ & $4.67 E+03$ & $3.50 \mathrm{E}+04$ & $2.80 \mathrm{E}+05$ & $4.18 \mathrm{E}+05$ \\
\hline & Dinner & $4.07 E+05$ & $1.45 \mathrm{E}+05$ & $4.53 E+02$ & $9.05 E+03$ & $5.62 \mathrm{E}+05$ \\
\hline & Snack \#3 & $1.43 E+05$ & $2.94 \mathrm{E}+03$ & $8.40 \mathrm{E}+01$ & $8.40 \mathrm{E}+01$ & $1.46 \mathrm{E}+05$ \\
\hline & Total & $2.77 E+06$ & $1.87 E+06$ & $5.78 \mathrm{E}+05$ & $7.92 E+05$ & $6.01 E+06$ \\
\hline
\end{tabular}


Table 2 (on next page)

Ingredients included in each meal.

A detailed accounting of each component of each meal, including the weight of each ingredient. 


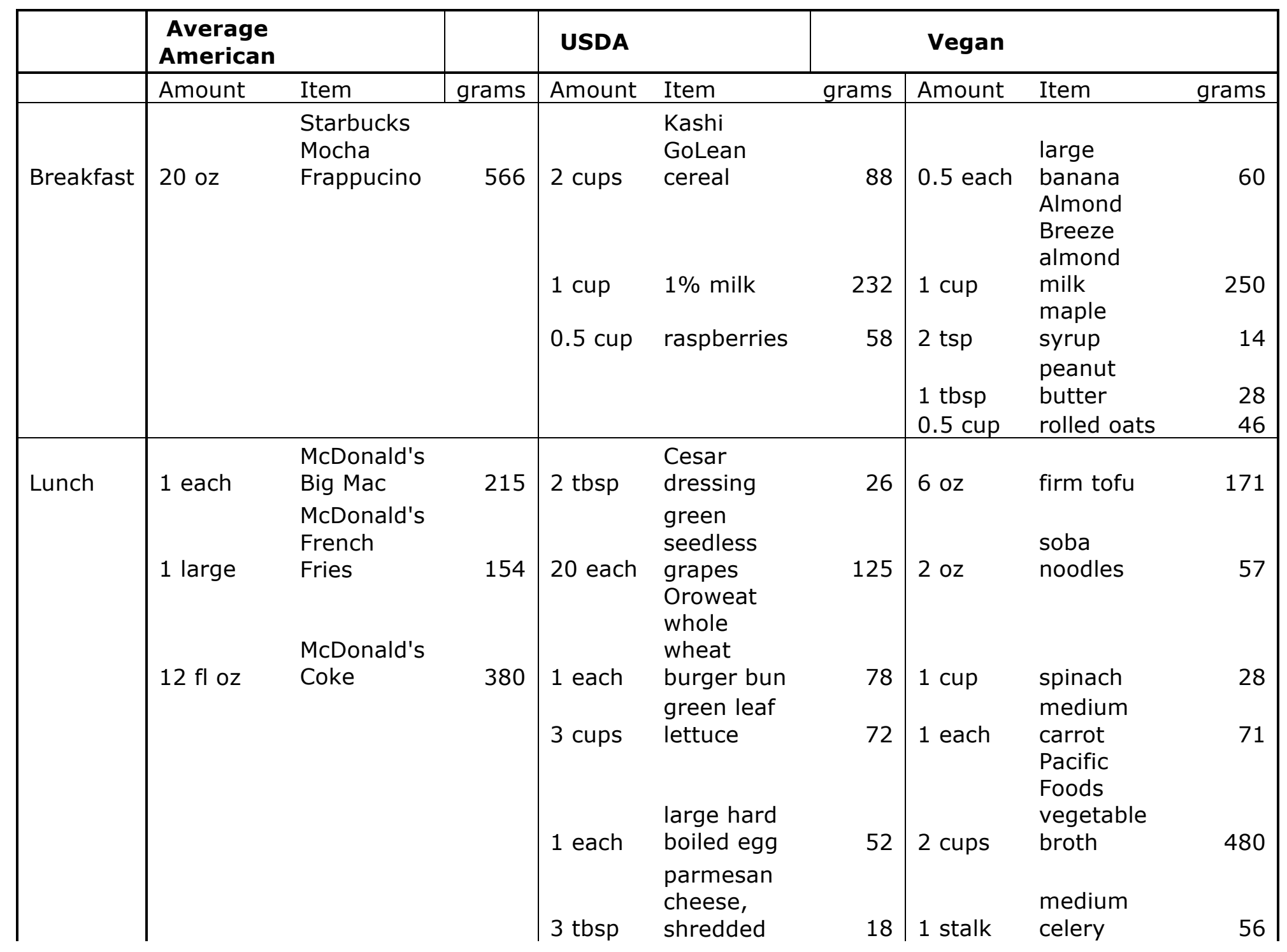




\begin{tabular}{|c|c|c|c|c|c|c|c|c|c|}
\hline & & & & 2 slices & $\begin{array}{l}\text { roasted } \\
\text { turkey } \\
\text { breast }\end{array}$ & 46 & $\begin{array}{l}0.25 \text { cup } \\
1 \text { tsp } \\
0.25 \text { tsp }\end{array}$ & $\begin{array}{l}\text { chopped } \\
\text { yellow } \\
\text { onion } \\
\text { extra virgin } \\
\text { olive oil } \\
\text { toasted } \\
\text { sesame oil } \\
\end{array}$ & 65 \\
\hline Dinner & 2 slices & $\begin{array}{l}\text { Stouffer's } \\
\text { Lasagna }\end{array}$ & 515 & $\begin{array}{l}1 \text { tbsp } \\
1 \text { cup } \\
0.33 \\
\text { cup } \\
4 \text { each } \\
0.5 \text { cup } \\
\\
6 \text { oz } \\
0.5 \text { cup } \\
1 \text { tsp } \\
1.5 \text { cup }\end{array}$ & $\begin{array}{l}\text { extra virgin } \\
\text { olive oil } \\
\text { quinoa } \\
\text { diced } \\
\text { yellow } \\
\text { onion } \\
\text { medium } \\
\text { asparagus } \\
\text { spears } \\
\text { frozen } \\
\text { green peas } \\
\text { boneless } \\
\text { skinless } \\
\text { chicken } \\
\text { poached } \\
\text { spinach } \\
\text { lemon juice } \\
\text { water }\end{array}$ & $\begin{array}{l}35 \\
65 \\
72\end{array}$ & $\begin{array}{l}1 \text { leaf } \\
1 \text { cup } \\
1 \text { tsp } \\
1 \text { clove } \\
1 \text { tbsp } \\
1 \text { bun }\end{array}$ & $\begin{array}{l}\text { red lettuce } \\
\text { chopped } \\
\text { broccoli } \\
\text { lemon juice } \\
\text { garlic } \\
\text { chopped } \\
\text { basil } \\
\text { Oroweat } \\
\text { whole } \\
\text { wheat } \\
\text { burger bun }\end{array}$ & $\begin{array}{r}38 \\
159 \\
14 \\
\\
14 \\
14 \\
57 \\
\\
\\
\\
14 \\
\\
80 \\
0.5 \\
0.5 \\
0.5\end{array}$ \\
\hline
\end{tabular}




\begin{tabular}{|c|c|c|c|c|c|c|c|c|c|}
\hline $\begin{array}{l}\text { Snack } \\
\# 1\end{array}$ & & & & $\begin{array}{l}1 \text { each } \\
6 \mathrm{oz}\end{array}$ & $\begin{array}{l}\text { small Fuji } \\
\text { apple } \\
\text { Yoplait } \\
\text { strawberry } \\
\text { yogurt }\end{array}$ & 163 & $\begin{array}{l}0.5 \text { each } \\
1 \text { cup } \\
1 \text { scoop } \\
1 \text { cup }\end{array}$ & $\begin{array}{l}\begin{array}{l}\text { large } \\
\text { banana }\end{array} \\
\text { soy milk } \\
\text { Spirutein } \\
\text { protein } \\
\text { powder } \\
\text { blueberries } \\
\text { (Chile) }\end{array}$ & $\begin{array}{r}250 \\
38 \\
142 \\
\end{array}$ \\
\hline $\begin{array}{l}\text { Snack } \\
\# 2\end{array}$ & 3 each & $\begin{array}{l}\text { Oreo } \\
\text { cookies }\end{array}$ & 34 & $\begin{array}{l}10 \text { each } \\
1 \text { cup } \\
2 \text { tbsp }\end{array}$ & $\begin{array}{l}\text { large baby } \\
\text { carrots } \\
2 \% \text { cottage } \\
\text { cheese } \\
\text { semi-sweet } \\
\text { chocolate } \\
\text { chips }\end{array}$ & $\begin{array}{r}82 \\
238\end{array}$ & $\begin{array}{l}1 \text { bag } \\
1 \text { cup } \\
1 \text { each } \\
20 \text { each }\end{array}$ & $\begin{array}{l}\text { green tea } \\
\text { water } \\
\text { medium } \\
\text { Fuji apple } \\
\text { almonds }\end{array}$ & $\begin{array}{r}0 \\
290 \\
\\
153 \\
24 \\
\end{array}$ \\
\hline $\begin{array}{l}\text { Snack } \\
\# 3\end{array}$ & & & & & & & $\begin{array}{l}2 \text { cups } \\
17 \text { each } \\
3 \text { each }\end{array}$ & $\begin{array}{l}\text { pop corn } \\
\text { hazelnuts } \\
\text { Newman's } \\
\text { Own fig } \\
\text { bars }\end{array}$ & $\begin{array}{l}12 \\
16\end{array}$ \\
\hline
\end{tabular}


Table 3(on next page)

Food preparation details.

The meal preparation and cooking instructions (when appropriate) are presented here. 


\section{Average American}

Used as purchased Breakfast from Starbucks.

Snack \#1

Cookies taken out of packaging.

Used as purchased

Lunch from McDonald's.

Snack

\section{USDA}

Cereal poured directly from box into bowl. Milk poured into measuring cup, then into cereal bowl. Raspberries washed first in colander under running water then transferred on top of cereal.

Apple washed and sliced, core discarded. Yogurt used as purchased.

Sliced roasted turkey breast deli meat take out of packaging and placed into burger bun. Lettuce rinsed in colander under running water and dried on paper towel then cut into strips and tossed with premade Cesar dressing. Egg boiled in water for 8 minutes then peeled and sliced in half and placed in top of dressed salad. Parmesan cheese shredded and added on top of salad. Grapes rinsed in colander under running water, then sliced in half and placed on top of salad.

Baby carrots taken out of packaging and used. Cottage cheese measured out in measuring cup. Chocolate chips measured out and used.
Vegan

Almond milk brought to a boil, then oats added and cooked for 5 minutes on low heat. Peanut butter and maple syrup measured out then stirred into cooked oats. Banana peeled and sliced into slices on top of cooked oats.

Soy milk measured into measuring cup, protein powder measured into scoop, banana peeled and cut in half, blueberries rinsed in colander under running water.

Carrot rinsed under running water, peeled, and sliced. Celery washed under running water and sliced. Onion outer layer peeled and diced. Sliced carrot, celery and onion sauteed in olive oil for 5 minutes, then vegetable broth measured out in measuring cup and added to vegetables, brought to a boil. Tofu taken out of packaging, excess water discarded, cut into cubes, added to broth. Spinach taken out of prepackaged, prerinsed bag and added to broth. Noodles and sesame oil added to broth. Soup cooked for 8 minutes on low heat.

Water boiled and poured into cup with tea bag, steeped for 5 minutes. Apple rinsed under running water, sliced, and core discarded. Almonds taken out of packaging. 
Lasagna prepared according to manufacturer instructions (taken out of freezer and baked at 400F for 1 hour and 45 minutes, cooled, Dinner then sliced.

\section{Chicken breast taken out of plastic} packaging, and placed into pot with boiling water, boiled for 3 minutes, removed from heat, covered, let stand for 18 minutes,

then sliced. Quinoa rinsed in colander under Mushroom destemmed and peeled, soaked in running water, added to water in pan and brought to a boil, simmered covered for 20 minutes. Oil heated in large skillet over medium heat, onion peeled and diced, asparagus spears rinsed and sliced, both added to oil and cooked for 5 minutes. Peas added from frozen packaging and cooked for 1 minute. Spinach rinsed in colander under running water and added to skillet, cooked for 3 minutes. Quinoa, vegetables, and chicken combined with lemon juice.
Snack

\#3 vinegar, then grilled in grill pan for 5 minutes on each side. Garlic peeled and grated into

Vegenaise, lemon juice added. Basil rinsed under running water, chopped and added to Vegenaise mixture. Tomato rinsed under running water, then sliced. Lettuce leaf rinsed under running water. Broccoli rinsed under running water, then steamed in colander for 3 minutes, chopped. Burger assembled: Vegenaise mixture spread onto bottom of bun, topped with mushroom, lettuce leaf, tomato slice and top of bun.

Popcorn (no salt, no oil) prepared in microwave bag as directed (placed in microwave for 4 minutes). Hazelnuts taken out of packaging. Fig bars taken out of packaging. 
Table 4(on next page)

Nutrient composition by meal.

Diet nutrient composition was calculated by the NutriHand program from reference nutrient data for individual foods using the USDA National Nutrient Database for Standard Reference. 


\begin{tabular}{|c|c|c|c|c|c|c|c|c|}
\hline $\begin{array}{l}\text { Dietary } \\
\text { Pattern/Meal }\end{array}$ & $\begin{array}{l}\text { Energy } \\
\text { (kcal) }\end{array}$ & Protein $(\mathrm{g})$ & $\begin{array}{l}\text { Total lipid } \\
\text { (fat) (g) }\end{array}$ & $\begin{array}{l}\text { Carbohydrate, by } \\
\text { difference }(g)\end{array}$ & $\begin{array}{l}\text { Fiber, total } \\
\text { dietary }(g)\end{array}$ & $\begin{array}{l}\text { Sugars, } \\
\text { total }(g)\end{array}$ & $\begin{array}{l}\text { Calcium, } \\
\text { Ca (mg) }\end{array}$ & $\begin{array}{l}\text { Iron, Fe } \\
\text { (mg) }\end{array}$ \\
\hline AMERICAN & & & & & & & & \\
\hline $\begin{array}{l}\text { Breakfast } \\
\text { AMERICAN }\end{array}$ & 367 & 8.52 & 4.98 & 73.33 & 0 & 60 & 250 & 1.2 \\
\hline $\begin{array}{l}\text { Lunch } \\
\text { AMERICAN }\end{array}$ & 1174 & 31.76 & 57.58 & 138.6 & 10 & 43.53 & 280 & 5.7 \\
\hline $\begin{array}{l}\text { Dinner } \\
\text { AMERICAN }\end{array}$ & 568 & 26.62 & 20.81 & 68.2 & 5.6 & 11.4 & 380 & 2.88 \\
\hline Snack & 160 & 1 & 7 & 25 & 1 & 14 & 20 & 1.8 \\
\hline USDA Breakfast & 414 & 34.96 & 4.85 & 79.52 & 24 & 27.41 & 466 & 4.09 \\
\hline USDA Snack \#1 & 256 & 8.91 & 3.07 & 52.29 & 3.6 & 20.45 & 268 & 0.3 \\
\hline USDA Lunch & 656 & 37.26 & 28.97 & 68.61 & 6 & 19.06 & 298 & 6.06 \\
\hline USDA Snack \#2 & 352 & 29.2 & 11.74 & 34.13 & 5.8 & 27.43 & 254 & 2.22 \\
\hline $\begin{array}{l}\text { USDA Dinner } \\
\text { VEGAN }\end{array}$ & 581 & 48.44 & 19.22 & 56.41 & 5.6 & 6.97 & 58 & 3 \\
\hline $\begin{array}{l}\text { Breakfast } \\
\text { VEGAN Snack }\end{array}$ & 367 & 10 & 12.78 & 58.19 & 6.7 & 28.31 & 311 & 0.9 \\
\hline \#1 & 373 & 23.76 & 4.95 & 62.8 & 7.7 & 40.46 & 373 & 6.65 \\
\hline $\begin{array}{l}\text { VEGAN Lunch } \\
\text { VEGAN Snack }\end{array}$ & 468 & 25.49 & 13.89 & 64.31 & 7 & 7.95 & 348 & 6.94 \\
\hline \#2 & 233 & 5.82 & 12.59 & 30.39 & 7.3 & 19.86 & 82 & 1.11 \\
\hline $\begin{array}{l}\text { VEGAN Dinner } \\
\text { VEGAN Snack }\end{array}$ & 444 & 15.4 & 20.19 & 55.62 & 16.3 & 13.74 & 176 & 3.5 \\
\hline \#3 & 378 & 7.41 & 18.69 & 50.46 & 6.8 & 23.42 & 59 & 3.02 \\
\hline
\end{tabular}

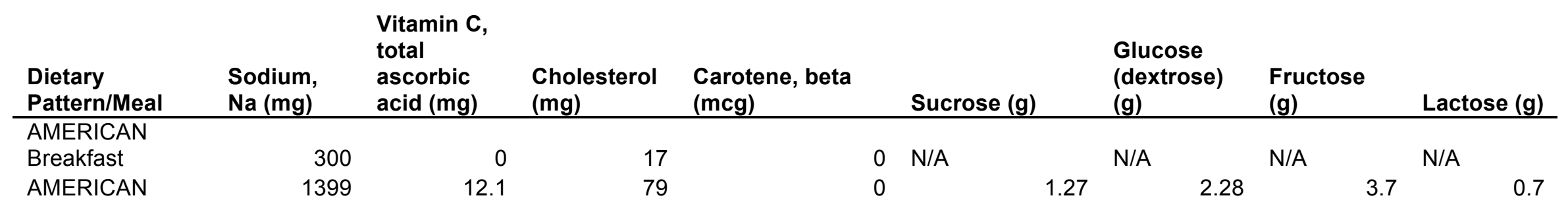


Lunch
AMERICAN

Dinner

Dinner
AMERICAN

Snack

USDA Breakfast

USDA Snack \#1

USDA Lunch

USDA Snack \#2

USDA Dinner

VEGAN

Breakfast

VEGAN Snack

\#1

VEGAN Lunch

VEGAN Snack

\#2

VEGAN Dinner VEGAN Snack \#3

$\begin{array}{rrrr}2102 & 7.2 & 56 & \text { N/A } \\ 160 & 0 & 0 & \text { N/A } \\ 278 & 16.1 & 12 & \\ 100 & 8 & 10 & 223 \\ 1516 & 110 & 23 & 90 \\ 863 & 3.9 & 85 \\ 446 & 25.6 & & \\ & & 0 \\ 312 & 6 & 0 \\ 266 & 80 & 0 \\ 1618 & 16.2 & 0 \\ 9 & 8.4 & 0 \\ 499 & 102.3 & \end{array}$

$\begin{array}{rr} & \text { N/A } \\ 61 & \text { N/A } \\ 47 & \\ 56 & \\ 9600 & \\ 1953 & \\ 18 \\ 69 \\ 6850 \\ 50 \\ 1018 \\ 17\end{array}$

0.12
3.08
0.15
4.08
3.78

3.14
1.79
2.65
4.63
0.11
1.12

N/A

1.14
3.62
7.2
3.3
1.58

8.49
10.47
1.4
4.45
6.96
0.03

N/A

1.45
8.79
8.1
1.
1.5
9.03
10.51
1.11
10.7
3.23
0.03

N/A

N/A

1.45

8.79

0

6.55

0

0

0

0

0

0.19

0

Fatty acids,

Fatty acids,

Fatty acids, total total

polyunsaturated Vitamin A, saturated

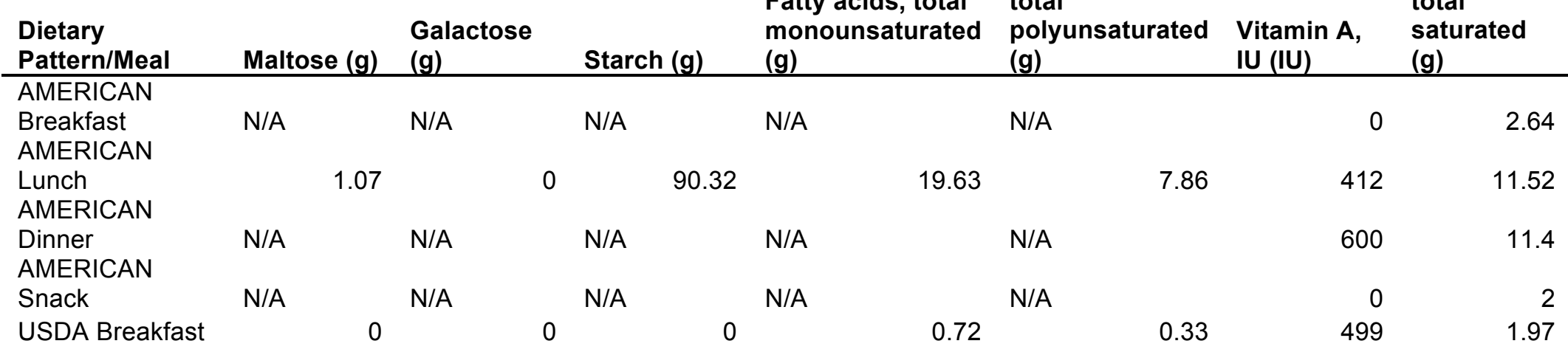


USDA Snack \#1 USDA Lunch

USDA Snack \#2

USDA Dinner

VEGAN

Breakfast

VEGAN Snack

\#1

VEGAN Lunch

VEGAN Snack

\#2

VEGAN Dinner VEGAN Snack \#3

$\begin{array}{rrr}0 & 0 & 0.07 \\ 0 & 0 & 0 \\ 0 & 0 & 0 \\ 0.05 & 0.02 & 2.79 \\ 0.21 & 0.43 & 4.43 \\ 0.01 & 0 & 3.7 \\ 0 & 0.29 & 0.87 \\ 0.01 & 0.01 & 0.27 \\ 0.19 & 0.01 & 0 \\ 0 & & \\ 0 & 0 & 8.81\end{array}$

1.16
7.71
1.01
9.88
3.9
1.06
5.9
7.99
10.74
12.48

0.55

11.43

0.27

1.61

2.32

2.6

5.82

3.48

5.56

3.51

$\begin{array}{rr}836 & 2.06 \\ 5179 & 7.29 \\ 20852 & 5.99 \\ 3271 & 1.97 \\ & \\ 544 & 2.25 \\ 5129 & 0.62 \\ 13184 & 1.79 \\ 102 & 1.48 \\ 1779 & 2.64 \\ 52 & 1.69\end{array}$


Table 5 (on next page)

Sequence summary statistics by meal.

The number of sequences per meal before and after filtration to remove eukaryotic, chimeric, and singleton reads, and the number of OTUs per meal after filtration. 


$\begin{array}{llll}\text { Meal } & \begin{array}{l}\text { \# Sequences Pre- } \\ \text { filtration }\end{array} & \begin{array}{l}\text { \# Sequences Post- } \\ \text { filtration }\end{array} & \begin{array}{l}\text { \# OTUs (open reference, 97\% } \\ \text { similarity) }\end{array} \\ \text { AMERICANbreakfast } & 267254 & 226903 & 1838 \\ \text { AMERICANdinner } & 298442 & 11666 & 660 \\ \text { AMERICANlunch } & 299035 & 96898 & 622 \\ \text { AMERICANsnack } & 311311 & 279136 & 969 \\ \text { USDAbreakfast } & 318956 & 5002 & 502 \\ \text { USDAdinner } & 277213 & 6149 & 476 \\ \text { USDAlunch } & 270166 & 16456 & 607 \\ \text { USDAsnack1 } & 299998 & 226403 & 334 \\ \text { USDAsnack2 } & 238057 & 104114 & 333 \\ \text { VEGANbreakfast } & 274360 & 7310 & 399 \\ \text { VEGANdinner } & 303246 & 3576 & 417 \\ \text { VEGANlunch } & 291459 & 13874 & 480 \\ \text { VEGANsnack1 } & 244886 & 62446 & 644 \\ \text { VEGANsnack2 } & 288319 & 974 & 1053 \\ \text { VEGANsnack3 } & 168669 & 54483 & 229\end{array}$


Table 6 (on next page)

Pairwise Pearson correlations between individual taxonomic groups and meal nutrient composition.

Pairwise Pearson correlation coefficients $(R)$ reveal significant correlations between some taxonomic groups and meal nutrient contents. Correlations were performed at 5 taxonomic levels (Phylum-Genus.) Only significant correlations are reported here $(*=p<0.05$, $* *=p<0.01)$. 


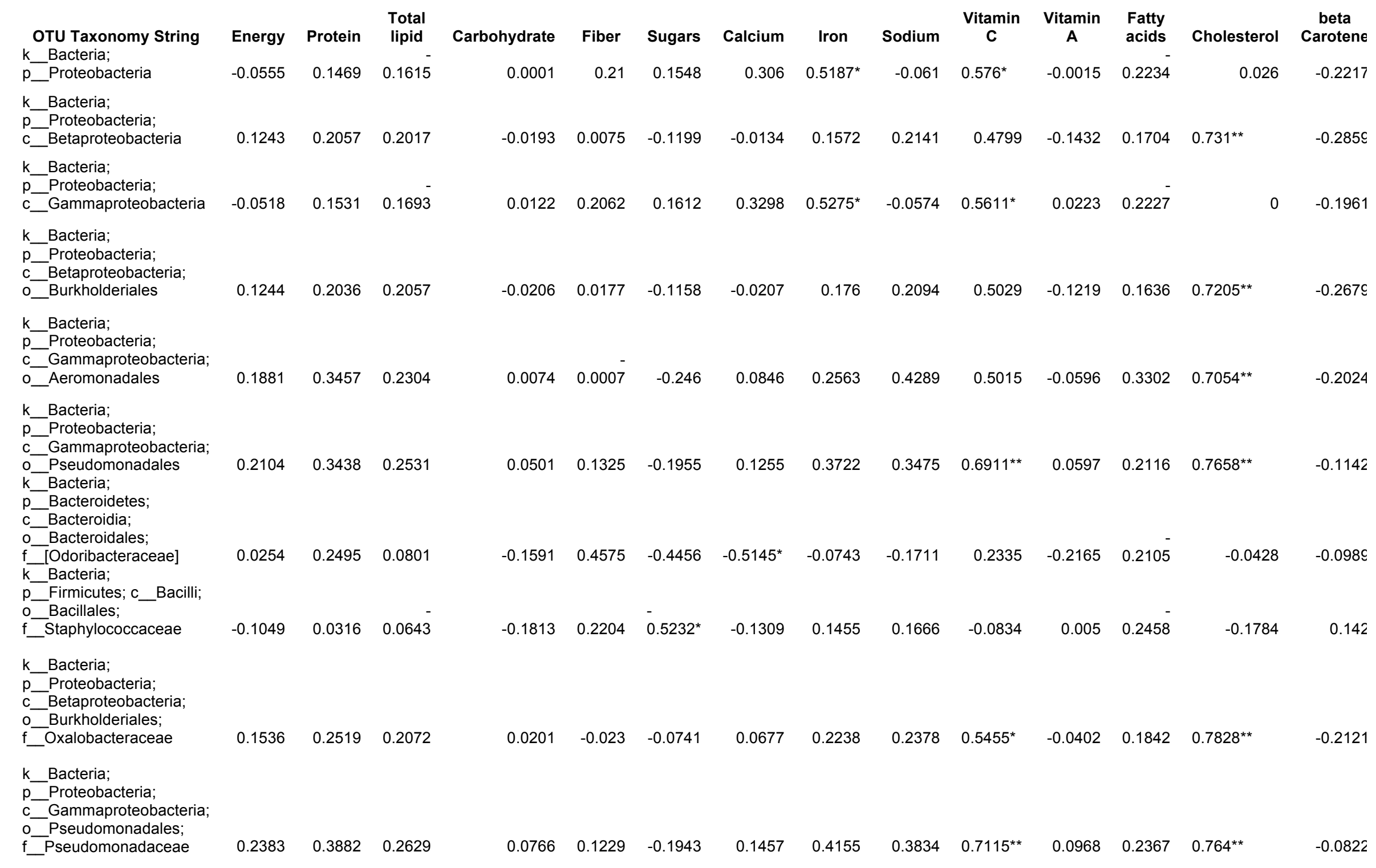


k__Bacteria;

p__Firmicutes; C_Bacilli;

o_Bacillales;

f_-Staphylococcaceae;

g_Staphylococcus

k_Bacteria;

p__Firmicutes; C_Bacilli;

o Lactobacillales:

$\mathrm{f}$ _-Streptococcaceae;

g_Lactococcus

k_Bacteria;

p_Firmicutes;

C_Clostridia;

o-Clostridiales;

f_Lachnospiraceae;

g_Blautia
$-0.1031$
$0.0343 \quad 0.0633$

$-0.1798$

0.222

$0.5254^{*}$

$-0.1292$

0.1482

0.1686

$-0.0819$

0.0068

$0.2455^{-}$

$-0.1771$

0.1437

$0.2088 \quad 0.2213 \quad 0.2812$

$0.0331 \quad 0.1385$

0.142

$-0.0006$

$-0.0765$

0.136

$-0.2465$

$0.603^{*}$

$-0.00240 .6236^{*}$

$\begin{array}{lll}-0.0198 & 0.1057 & 0.028\end{array}$

$\begin{array}{lll}-0.1283 & 0.3711 & 0.5586^{*}\end{array}$

$-0.2554$

0.2255

0.1582

0.0478

0.0257

0.2386

$-0.2277$

0.1791

p Proteobacteria;

c__Gammaproteobacteria

o - Pseudomonadales;

f_Pseudomonadaceae;

g_Pseudomonas

$0.2379 \quad 0.3875 \quad 0.2629$
$0.0764 \quad 0.1225 \quad-0.1935$

0.1452

0.4149
0.0964

0.236

$0.7645^{\star *}$

$-0.082 \varepsilon$ 
Table 7 (on next page)

PCR primer constructs for Illumina MiSeq 16S rDNA amplicon sequencing.

16S rDNA PCR was performed using these primers that include adaptors necessary for

binding to the Illumina MiSeq flow cell, a spacer sequence, an $8 \mathrm{bp}$ barcode sequence, and the "universal" 16S rDNA primers 515F and 806R. 


\begin{tabular}{|c|c|c|c|c|c|c|}
\hline Name & ipter sequence & barcode & pad & $\operatorname{lin}_{\text {ker }}$ & rimer & Oligo \\
\hline 5 & $\begin{array}{l}\text { AATGATACGGCGACC } \\
\text { CGAGATCTACAC }\end{array}$ & $\begin{array}{l}\text { AACC } \\
\text { AGTC }\end{array}$ & $\begin{array}{l}\text { TAT } \\
\text { AAT }\end{array}$ & TG & $\begin{array}{l}\text { TGCC } \\
\text { GCGC }\end{array}$ & $\begin{array}{l}\text { AATGATACGGCGACCACCGAGATCTACACAACCAGTCTATG } \\
\text { GTAATTGTGTGCCAGCMGCCGCGGTAA }\end{array}$ \\
\hline $\begin{array}{l}\text { S5 } 515 \\
2\end{array}$ & $\begin{array}{l}\text { AATGATACGGCGACCAC } \\
\text { CGAGATCTACAC }\end{array}$ & $\begin{array}{l}\text { AACG } \\
\text { CTAA }\end{array}$ & & $\mathrm{TG}$ & $\begin{array}{l}\text { TGCCAGCMGCC } \\
\text { GCGGTAA }\end{array}$ & $\begin{array}{l}\text { AATGATACGGCGACCACCGAGATCTACACAACGCTAATATG } \\
\text { GTAATTGTGTGCCAGCMGCCGCGGTAA }\end{array}$ \\
\hline 35 & CGAG & $\begin{array}{l}\text { AAGA } \\
\text { CTAC }\end{array}$ & $\mathrm{AA}^{\prime}$ & TG & $\begin{array}{l}\text { TGCC } \\
\text { GCG }\end{array}$ & $\begin{array}{l}\text { CACAAGACTACTATG } \\
\text { A }\end{array}$ \\
\hline $\begin{array}{l}\text { S515 } \\
4\end{array}$ & $\begin{array}{l}\text { AATGATACGGCGACCAC } \\
\text { CGAGATCTACAC }\end{array}$ & $\begin{array}{l}\text { AATC } \\
\text { GATA }\end{array}$ & $\begin{array}{l}\text { TATGGT } \\
\text { AATTG }\end{array}$ & $\mathrm{TG}$ & $\begin{array}{l}\text { TGCCAGCM } \\
\text { GCGGTAA }\end{array}$ & $\begin{array}{l}\text { AATGATACGGCGACCACCGAGATCTACACAATCGATATATG } \\
\text { GTAATTGTGTGCCAGCMGCCGCGGTAA }\end{array}$ \\
\hline $\begin{array}{l}6 \mathrm{~S} 515 \\
\mathrm{c} 5\end{array}$ & $\begin{array}{l}\text { AATGATACGGCGACCAC } \\
\text { CGAGATCTACAC }\end{array}$ & $\begin{array}{l}\text { ACCA } \\
\text { ATTG }\end{array}$ & & TG & $\begin{array}{l}\text { TGCCAGCMGCC } \\
\text { GCGGTAA }\end{array}$ & $\begin{array}{l}\text { ATGATACGGCGACCACCGAGATCTACACACCAATTGTATG } \\
\text { TAATTGTGTGCCAGCMGCCGCGGTAA }\end{array}$ \\
\hline $\begin{array}{l}6 \mathrm{~S} 515 \\
6\end{array}$ & $\begin{array}{l}\text { AATG } \\
\text { CGAG }\end{array}$ & $\begin{array}{l}\text { ACTG } \\
\text { AAGT }\end{array}$ & & TG & $\begin{array}{l}\text { TGC } \\
\text { GCC }\end{array}$ & TGAAGTTATG \\
\hline $\begin{array}{l}6 \mathrm{~S} 515 \\
\mathrm{c} 7\end{array}$ & $\begin{array}{l}\text { AATGATACGGCGACCA } \\
\text { CGAGATCTACAC }\end{array}$ & $\begin{array}{l}\text { ATTGC } \\
\text { CGC }\end{array}$ & $\begin{array}{l}\text { TATGGT } \\
\text { AATTG }\end{array}$ & TG & $\begin{array}{l}\text { TGCCAGCM } \\
\text { GCGGTAA }\end{array}$ & TAATTGTGTGCCAGCMGCC \\
\hline $\begin{array}{l}\text { S515 } \\
8\end{array}$ & $\begin{array}{l}\text { AATGATACGGCGACCAC } \\
\text { CGAGATCTACAC }\end{array}$ & $\begin{array}{l}\text { CAAC } \\
\text { CTTA }\end{array}$ & & TG & $\begin{array}{l}\text { TGCCAGC } \\
\text { GCGGTAA }\end{array}$ & ATGATACGO \\
\hline $\begin{array}{l}6 \mathrm{~S} 515 \\
\mathrm{c} 9\end{array}$ & $\begin{array}{l}\text { AATGATACGGCGACCAC } \\
\text { CGAGATCTACAC }\end{array}$ & $\begin{array}{l}\text { CCTAA } \\
\text { TAA }\end{array}$ & $\begin{array}{l}\text { TATGGT } \\
\text { AATTG }\end{array}$ & TG & $\begin{array}{l}\text { TGCCAGCMGCC } \\
\text { GCGGTAA }\end{array}$ & $\begin{array}{l}\text { AATGATACGGCGACCACCGAGATCTACACCCTAATAATATG } \\
\text { GTAATTGTGTGCCAGCMGCCGCGGTAA }\end{array}$ \\
\hline $\begin{array}{l}6 \mathrm{~S} 515 \\
\mathrm{c} 10\end{array}$ & $\begin{array}{l}\text { AATGATACGGCGACCAC } \\
\text { CGAGATCTACAC }\end{array}$ & $\begin{array}{l}\text { CCTCT } \\
\text { GAT }\end{array}$ & $\begin{array}{l}\text { TATGGT } \\
\text { AATTG }\end{array}$ & TG & $\begin{array}{l}\text { TGCCAGCM } \\
\text { GCGGTAA }\end{array}$ & CCCTCTGATTATGG \\
\hline $\begin{array}{l}6 \mathrm{~S} 515 \\
\mathrm{c} 11\end{array}$ & $\begin{array}{l}\text { AATGATACGGCGACCAC } \\
\text { CGAGATCTACAC }\end{array}$ & $\begin{array}{l}\text { CGGTC } \\
\text { GAG }\end{array}$ & $\begin{array}{l}\text { TATGGT } \\
\text { AATTG }\end{array}$ & TG & $\begin{array}{l}\text { TGCCAGCMGC } \\
\text { GCGGTAA }\end{array}$ & $\begin{array}{l}\text { TACGGCGACCACCGAGATCTACAC } \\
\text { TGTGTGCCAGCMGCCGCGGTAA }\end{array}$ \\
\hline $\begin{array}{l}16 \mathrm{~S} 515 \\
\mathrm{bc} 12\end{array}$ & $\begin{array}{l}\text { AATGATACGGCGACCAC } \\
\text { CGAGATCTACAC }\end{array}$ & $\begin{array}{l}\text { CTAAT } \\
\text { GGC }\end{array}$ & $\begin{array}{l}\text { TATGGT } \\
\text { AATTG }\end{array}$ & TG & $\begin{array}{l}\text { TGCCAGCMGCC } \\
\text { GCGGTAA }\end{array}$ & $\begin{array}{l}\text { AATGATACGGCGACCACCGAGATCTACACCTAATG } \\
\text { GTAATTGTGTGCCAGCMGCCGCGGTAA }\end{array}$ \\
\hline $\begin{array}{l}6 \mathrm{~S} 515 \\
\mathrm{c} 13\end{array}$ & $\begin{array}{l}\text { AATGATACGGCGACCAC } \\
\text { CGAGATCTACAC }\end{array}$ & $\begin{array}{l}\text { CTCAT } \\
\text { GCG }\end{array}$ & $\begin{array}{l}\text { TATGGT } \\
\text { AATTG }\end{array}$ & TG & $\begin{array}{l}\text { TGCCAGCMGCC } \\
\text { GCGGTAA }\end{array}$ & $\begin{array}{l}\text { AATGATACGGCGACCACCGAGATCTACACCTCATGCGTATGG } \\
\text { TAATTGTGTGCCAGCMGCCGCGGTAA }\end{array}$ \\
\hline $\begin{array}{l}16 \mathrm{~S} 515 \\
\mathrm{bc} 14\end{array}$ & $\begin{array}{l}\text { AATGATACGGCGACCAC } \\
\text { CGAGATCTACAC }\end{array}$ & $\begin{array}{l}\text { GAAC } \\
\text { GGAG }\end{array}$ & $\begin{array}{l}\text { TATGGT } \\
\text { AATTG }\end{array}$ & $\mathrm{TG}$ & $\begin{array}{l}\text { TGCCAGCMGCC } \\
\text { GCGGTAA }\end{array}$ & $\begin{array}{l}\text { AATGATACGGCGACCACCGAGATCTACACGAACGGAGTATG } \\
\text { GTAATTGTGTGCCAGCMGCCGCGGTAA }\end{array}$ \\
\hline $16 \mathrm{~S} 515$ & AATGATACGGCGACCAC & GCCTA & TATGGT & TG & TGCCAGCMGCC & AATGATACGGCGACCACCGAGATCTACACGCCTACGCTATG \\
\hline
\end{tabular}




\begin{tabular}{|c|c|c|c|c|c|c|}
\hline Name & Illumina adapter sequence & barcode & pad & $\operatorname{lin}_{\text {ker }}$ & rimer & Complete Oligo \\
\hline 15 & CGAGATCTACAC & CGC & AATTG & & GCGGTAA & GTAATTGTGTGCCAGCMGCCGCGGTAA \\
\hline 0 & $\begin{array}{l}\text { AATGATACGGCGACC } \\
\text { CGAGATCTACAC }\end{array}$ & $\begin{array}{l}\text { GCGTT } \\
\text { ACC }\end{array}$ & $\begin{array}{l}\text { TATC } \\
\text { AAT }\end{array}$ & TG & $\begin{array}{l}\text { TGCC } \\
\text { GCGC }\end{array}$ & $\begin{array}{l}\text { AATGATACGGCGACCACCGAGATCTACA } \\
\text { TAATTGTGTGCCAGCMGCCGCGGTAA }\end{array}$ \\
\hline & $\begin{array}{l}\text { AATGATACGGCGACCAC } \\
\text { CGAGATCTACAC }\end{array}$ & & & TG & $\begin{array}{l}\text { TGCCAGCMGCC } \\
\text { GCGGTAA }\end{array}$ & $\begin{array}{l}\text { AATGATACGGCGACCACCGAGATCTACACGGAGGCTGTATG } \\
\text { GTAATTGTGTGCCAGCMGCCGCGGTAA }\end{array}$ \\
\hline 10 & $\begin{array}{l}\text { AATG } \\
\text { CGAG }\end{array}$ & $\begin{array}{l}\text { GGAT } \\
\text { GCCA }\end{array}$ & & TG & MGCC & AACGGATGCCATATG \\
\hline 13 & $\begin{array}{l}\text { AATGATACG } \\
\text { CGAGATCTAC }\end{array}$ & $\begin{array}{l}\text { GGATT } \\
\text { AGG }\end{array}$ & $\begin{array}{l}\text { TATGGT } \\
\text { AATTG }\end{array}$ & TG & $\begin{array}{l}\text { TGCCAGCMGC } \\
\text { GCGGTAA }\end{array}$ & $\begin{array}{l}\text { SAGATCTACACGGATTAGGTATG } \\
\text { CCGCGGTAA }\end{array}$ \\
\hline $6 \mathrm{~S} 515$ & $\begin{array}{l}\text { AATGATACGGCGACCAC } \\
\text { CGAGATCTACAC }\end{array}$ & $\begin{array}{l}\text { GTTGG } \\
\text { CCG }\end{array}$ & & TG & $\begin{array}{l}\text { TGCCAGCM } \\
\text { GCGGTAA }\end{array}$ & $\begin{array}{l}\text { AATGATACGGCGACCACCGAGATCTACACGTTGGCCGTATG } \\
\text { GTAATTGTGTGCCAGCMGCCGCGGTAA }\end{array}$ \\
\hline $\begin{array}{l}16 \mathrm{~S} 515 \\
\mathrm{bc} 21\end{array}$ & $\begin{array}{l}\text { AATGATACGGCGACCAC } \\
\text { CGAGATCTACAC }\end{array}$ & $\begin{array}{l}\text { TATTA } \\
\text { ACT }\end{array}$ & $\begin{array}{l}\text { TATGGT } \\
\text { AATTG }\end{array}$ & $\mathrm{TG}$ & $\begin{array}{l}\text { TGCCAGCMGCC } \\
\text { GCGGTAA }\end{array}$ & TAATTGTGTGCCAGCMGCCGCGGTAA \\
\hline $6 \mathrm{~S} 515$ & $\begin{array}{l}\text { AATGA } \\
\text { CGAG }\end{array}$ & $\begin{array}{l}\text { TGACT } \\
\text { GCT }\end{array}$ & & TG & $\begin{array}{l}\text { TGCC } \\
\text { GCGC }\end{array}$ & ТА А СТGА СТСCТТАТТG \\
\hline S515 & $\begin{array}{l}\text { AATGATACGGCG } \\
\text { CGAGATCTACAC }\end{array}$ & $\begin{array}{l}\text { TGGCG } \\
\text { ATT }\end{array}$ & & TG & $\begin{array}{l}\text { TGCCAGCM } \\
\text { GCGGTAA }\end{array}$ & IAAT TUIUIUCCAUCN \\
\hline $\begin{array}{l}16 \mathrm{~S} 515 \\
\text { bc24 }\end{array}$ & $\begin{array}{l}\text { AATGATACGGCGACCAC } \\
\text { CGAGATCTACAC }\end{array}$ & $\begin{array}{l}\text { TTCAG } \\
\text { CGA }\end{array}$ & $\begin{array}{l}\text { TATGGT } \\
\text { AATTG }\end{array}$ & TG & $\begin{array}{l}\text { TGCCAGCMGCC } \\
\text { GCGGTAA }\end{array}$ & $\begin{array}{l}\text { AATGATACC } \\
\text { GTAATTGTC }\end{array}$ \\
\hline S515 & $\begin{array}{l}\text { AATGATACGGCGACCAC } \\
\text { CGAGATCTACAC }\end{array}$ & $\begin{array}{l}\text { TTGGC } \\
\text { TAT }\end{array}$ & $\begin{array}{l}\text { TATGGT } \\
\text { AATTG }\end{array}$ & $\mathrm{TG}$ & $\begin{array}{l}\text { TGCCAGC } \\
\text { GCGGTA }\end{array}$ & AA \\
\hline $\begin{array}{l}16 \mathrm{~S} 806 \\
R \mathrm{bc} 1\end{array}$ & $\begin{array}{l}\text { AATGATACGGCGACCAC } \\
\text { CGAGATCTACAC }\end{array}$ & $\begin{array}{l}\text { AACC } \\
\text { AGTC }\end{array}$ & GTCAG & $\mathrm{CC}$ & $\begin{array}{l}\text { GGACTACHVGG } \\
\text { GTWTCTAAT }\end{array}$ & $\begin{array}{l}\text { CACCGAGATCTACACAACCAGTCAGTC } \\
\text { CHVGGGTWTCTAAT }\end{array}$ \\
\hline $\begin{array}{l}16 \mathrm{~S} 806 \\
R \mathrm{bc} 2\end{array}$ & $\begin{array}{l}\text { AATGATACGGCGACC } \\
\text { CGAGATCTACAC }\end{array}$ & $\begin{array}{l}\text { AACG } \\
\text { CTAA }\end{array}$ & $\begin{array}{l}\text { AGTCA } \\
\text { TCAG }\end{array}$ & $\mathrm{CC}$ & $\begin{array}{l}\text { GGACTACHVGG } \\
\text { GTWTCTAAT }\end{array}$ & $\begin{array}{l}\text { AATGATACGGCGACCACCGAGATCTACACAACGCTAAAGTC } \\
\text { AGTCAGCCGGACTACHVGGGTWTCTAAT }\end{array}$ \\
\hline $\begin{array}{l}16 \mathrm{~S} 806 \\
R \mathrm{bc} 3\end{array}$ & $\begin{array}{l}\text { AATGATACGGCGACCAC } \\
\text { CGAGATCTACAC }\end{array}$ & $\begin{array}{l}\text { AAGA } \\
\text { CTAC }\end{array}$ & $\begin{array}{l}\text { AGTCAG } \\
\text { TCAG }\end{array}$ & $\mathrm{CC}$ & $\begin{array}{l}\text { GGACTACHVGG } \\
\text { GTWTCTAAT }\end{array}$ & $\begin{array}{l}\text { AATGATACGGCGACCACCGAGATCTACACAAGACTACAGTC } \\
\text { AGTCAGCCGGACTACHVGGGTWTCTAAT }\end{array}$ \\
\hline $\begin{array}{l}16 \mathrm{~S} 806 \\
R \mathrm{bc} 4\end{array}$ & $\begin{array}{l}\text { AATGATACGGCGACCAC } \\
\text { CGAGATCTACAC }\end{array}$ & $\begin{array}{l}\text { AATC } \\
\text { GATA }\end{array}$ & $\begin{array}{l}\text { AGTCAG } \\
\text { TCAG }\end{array}$ & $\mathrm{C}$ & $\begin{array}{l}\text { GGACTACHVGG } \\
\text { GTWTCTAAT }\end{array}$ & $\begin{array}{l}\text { AATGATACGGCGACCACCGAGATCTACAC } A \\
\text { AGTCAGCCGGACTACHVGGGTWTCTAAT }\end{array}$ \\
\hline
\end{tabular}




\begin{tabular}{|c|c|c|c|c|c|c|}
\hline Name & Illum & barcode & pad & $\begin{array}{l}\operatorname{lin} \\
\text { ker }\end{array}$ & primer & Complete Oligo \\
\hline $16 \mathrm{~S} 806$ & AATGATACGGCGACCAC & ACCA & AGTCAG & $\mathrm{CC}$ & GGACTACHVGG & CGAGATCTACACACCAATTGAGTC \\
\hline 80 & ATGATACGGCG & ACTG & & $\mathrm{CC}$ & GGA & AATGATACGGCGACC \\
\hline $\begin{array}{l}16 \mathrm{~S} 806 \\
R \mathrm{bc} 7\end{array}$ & $\begin{array}{l}\text { AATC } \\
\text { CGAC }\end{array}$ & $\begin{array}{l}\text { ATTGC } \\
\text { CGC }\end{array}$ & $\mathrm{TC} A$ & $\mathrm{CC}$ & $\begin{array}{l}\text { GGA } \\
\text { GTW }\end{array}$ & ГС \\
\hline $\begin{array}{l}16 \mathrm{~S} 806 \\
R \mathrm{bc} 8\end{array}$ & $\begin{array}{l}\text { AATGATACGGCGACCA } \\
\text { CGAGATCTACAC }\end{array}$ & $\begin{array}{l}\text { CAAC } \\
\text { CTTA }\end{array}$ & $\begin{array}{l}\text { AGTCA } \\
\text { TCAG }\end{array}$ & $\mathrm{CC}$ & $\begin{array}{l}\text { GGACTACHVGG } \\
\text { GTWTCTAAT }\end{array}$ & AGTCAGCCGGACTACHVGGGTWTCTAAT \\
\hline $\begin{array}{l}16 \mathrm{~S} 806 \\
R \text { bc9 }\end{array}$ & $\begin{array}{l}\text { AATGATACGGCGACCAC } \\
\text { CGAGATCTACAC }\end{array}$ & $\begin{array}{l}\text { CCTAA } \\
\text { TAA }\end{array}$ & $\begin{array}{l}\text { AGTCA } \\
\text { TCAG }\end{array}$ & $\mathrm{CC}$ & $\begin{array}{l}\text { GGACTACHVC } \\
\text { GTWTCTAAT }\end{array}$ & $\begin{array}{l}\text { AATGATACGGCGACCACCGAGATCTACACCCTAATAAAGTC } \\
\text { AGTCAGCCGGACTACHVGGGTWTCTAAT }\end{array}$ \\
\hline $\begin{array}{l}16 \mathrm{~S} 806 \\
R \mathrm{bc} 10\end{array}$ & $\begin{array}{l}\text { AATGA } \\
\text { CGAG } A\end{array}$ & $\begin{array}{l}\text { CCTCT } \\
\text { GAT }\end{array}$ & $\begin{array}{l}\text { AGT } \\
\text { TCA }\end{array}$ & $\mathrm{CC}$ & GG & $\begin{array}{l}\text { ACACCCTCTGATAGTCA } \\
\text { AT }\end{array}$ \\
\hline $\begin{array}{l}16 \mathrm{~S} 806 \\
R \mathrm{bc} 11\end{array}$ & $\begin{array}{l}\text { AATGATACGGCGACCAC } \\
\text { CGAGATCTACAC }\end{array}$ & $\begin{array}{l}\text { CGGTC } \\
\text { GAG }\end{array}$ & $\begin{array}{l}\text { AGTCAG } \\
\text { TCAG }\end{array}$ & $\mathrm{CC}$ & $\begin{array}{l}\text { GGACTACHVGG } \\
\text { GTWTCTAAT }\end{array}$ & $\begin{array}{l}\text { AATGATACGGCGACCACCGAGATCTACACCGGTCGAGAG } \\
\text { AGTCAGCCGGACTACHVGGGTWTCTAAT }\end{array}$ \\
\hline $\begin{array}{l}16 \mathrm{~S} 806 \\
R \mathrm{bc} 12\end{array}$ & $\begin{array}{l}\text { AATGATACGGCGACCAC } \\
\text { CGAGATCTACAC }\end{array}$ & $\begin{array}{l}\text { CTAAT } \\
\text { GGC }\end{array}$ & $\begin{array}{l}\text { AGTCAG } \\
\text { TCAG }\end{array}$ & $\mathrm{CC}$ & $\begin{array}{l}\text { GGACTACHVGG } \\
\text { GTWTCTAAT }\end{array}$ & $\begin{array}{l}\text { AATGATACGGCGACCACCGAGATCTACACCTAATGGCAGTC } \\
\text { AGTCAGCCGGACTACHVGGGTWTCTAAT }\end{array}$ \\
\hline $\begin{array}{l}16 \mathrm{~S} 806 \\
R \mathrm{bc} 13\end{array}$ & $\begin{array}{l}\text { AATGATACGGCGACCAC } \\
\text { CGAGATCTACAC }\end{array}$ & $\begin{array}{l}\text { CTCAT } \\
\text { GCG }\end{array}$ & $\begin{array}{l}\text { AGTCAG } \\
\text { TCAG }\end{array}$ & $\mathrm{CC}$ & $\begin{array}{l}\text { GGACTACHVGG } \\
\text { GTWTCTAAT }\end{array}$ & $\begin{array}{l}\text { AATGATACGGCGACCACCGAGATCTACACCTCATGCGAGTC } \\
\text { AGTCAGCCGGACTACHVGGGTWTCTAAT }\end{array}$ \\
\hline $\begin{array}{l}16 \mathrm{~S} 806 \\
R \mathrm{bc} 14\end{array}$ & $\begin{array}{l}\text { AATGATACGGCGACCAC } \\
\text { CGAGATCTACAC }\end{array}$ & $\begin{array}{l}\text { GAAC } \\
\text { GGAG }\end{array}$ & $\begin{array}{l}\text { AGTCAG } \\
\text { TCAG }\end{array}$ & $\mathrm{CC}$ & $\begin{array}{l}\text { GGACTACHVGG } \\
\text { GTWTCTAAT }\end{array}$ & $\begin{array}{l}\text { AATGATACGGCGACCACCGAGATCTACACGAACGGAGAGTC } \\
\text { AGTCAGCCGGACTACHVGGGTWTCTAAT }\end{array}$ \\
\hline $\begin{array}{l}16 \mathrm{~S} 806 \\
R \mathrm{bc} 15\end{array}$ & $\begin{array}{l}\text { AATGATACGGCGACCAC } \\
\text { CGAGATCTACAC }\end{array}$ & $\begin{array}{l}\text { GCCTA } \\
\text { CGC }\end{array}$ & $\begin{array}{l}\text { AGTCAG } \\
\text { TCAG }\end{array}$ & $\mathrm{CC}$ & VGG & $\begin{array}{l}\text { TACACGCCTACGCAGTC } \\
\text { CTAAT }\end{array}$ \\
\hline $\begin{array}{l}16 \mathrm{~S} 806 \\
R \mathrm{bc} 16\end{array}$ & $\begin{array}{l}\text { AATGATACGGCGACCAC } \\
\text { CGAGATCTACAC }\end{array}$ & $\begin{array}{l}\text { GCGTT } \\
\text { ACC }\end{array}$ & $\begin{array}{l}\text { AGTCAG } \\
\text { TCAG }\end{array}$ & $\mathrm{CC}$ & $\begin{array}{l}\text { GGACTACHVGG } \\
\text { GTWTCTAAT }\end{array}$ & $\begin{array}{l}\text { AATGATACGGCGACCACCGAGATCTACACGCGTTACCAGTC } \\
\text { AGTCAGCCGGACTACHVGGGTWTCTAAT }\end{array}$ \\
\hline $\begin{array}{l}16 \mathrm{~S} 806 \\
R \mathrm{bc} 17\end{array}$ & $\begin{array}{l}\text { AATGATACGGCGACCAC } \\
\text { CGAGATCTACAC }\end{array}$ & $\begin{array}{l}\text { GGAG } \\
\text { GCTG }\end{array}$ & $\begin{array}{l}\text { AGTCAG } \\
\text { TCAG }\end{array}$ & $\mathrm{CC}$ & $\begin{array}{l}\text { GGACTACHVGG } \\
\text { GTWTCTAAT }\end{array}$ & $\begin{array}{l}\text { AATGATACGGCGACCACCGAGATCTACACGGAGGCTGAGTC } \\
\text { AGTCAGCCGGACTACHVGGGTWTCTAAT }\end{array}$ \\
\hline $\begin{array}{l}16 \mathrm{~S} 806 \\
R \mathrm{bc} 18\end{array}$ & $\begin{array}{l}\text { AATGATACGGCGACCAC } \\
\text { CGAGATCTACAC }\end{array}$ & $\begin{array}{l}\text { GGAT } \\
\text { GCCA }\end{array}$ & $\begin{array}{l}\text { AGTCAG } \\
\text { TCAG }\end{array}$ & $\mathrm{C}$ & $\begin{array}{l}\text { GGACTACHVGG } \\
\text { GTWTCTAAT }\end{array}$ & $\begin{array}{l}\text { AATGATACGGCGACCACCGAGATCTACACGGATGCCAAGTC } \\
\text { AGTCAGCCGGACTACHVGGGTWTCTAAT }\end{array}$ \\
\hline $16 \mathrm{~S} 806$ & AATGATACGGCGACCAC & GGATT & AGTCAG & $\mathrm{CC}$ & GGACTACHVGG & AATGATACGGCGACCACCGAGATCTACACGGATTAGGAGTC \\
\hline
\end{tabular}




\begin{tabular}{|c|c|c|c|c|c|c|}
\hline Name & Illumina adapter sequence & barcode & pad & $\begin{array}{l}\operatorname{lin} \\
\text { ker }\end{array}$ & primer & Complete Oligo \\
\hline bc19 & CGAGATCTACAC & AGG & TCAG & & GTWTCTAAT & AGTCAGCCGGACTACHVGGGTWTCTAAT \\
\hline $\begin{array}{l}16 \mathrm{~S} 806 \\
R \mathrm{bc} 20\end{array}$ & $\begin{array}{l}\text { AATGATACGGCGACCAC } \\
\text { CGAGATCTACAC }\end{array}$ & $\begin{array}{l}\text { GTTGG } \\
\text { CCG }\end{array}$ & $\begin{array}{l}\text { AGTCAG } \\
\text { TCAG }\end{array}$ & $\mathrm{CC}$ & $\begin{array}{l}\text { GGA } \\
\text { GTW }\end{array}$ & $\begin{array}{l}\text { ACGTTGGCCGAGTC } \\
\text { AT }\end{array}$ \\
\hline $\begin{array}{l}16 \mathrm{~S} 806 \\
R \mathrm{bc} 21\end{array}$ & $\begin{array}{l}\text { AATGATACGGCGACC } \\
\text { CGAGATCTACAC }\end{array}$ & $\begin{array}{l}\text { TATTA } \\
\text { ACT }\end{array}$ & $\begin{array}{l}\text { AGTCAG } \\
\text { TCAG }\end{array}$ & $\mathrm{CC}$ & $\begin{array}{l}\text { GGACTACHVGG } \\
\text { GTWTCTAAT }\end{array}$ & $\begin{array}{l}\text { AATGATACGGCGACCACCGAGATCTACACTATTAACTAGT } \\
\text { GTCAGCCGGACTACHVGGGTWTCTAAT }\end{array}$ \\
\hline $\begin{array}{l}16 \mathrm{~S} 806 \\
R \mathrm{bc} 22\end{array}$ & $\begin{array}{l}\text { AATGATACGGCGACCAC } \\
\text { CGAGATCTACAC }\end{array}$ & $\begin{array}{l}\text { TGACT } \\
\text { GCT }\end{array}$ & $\begin{array}{l}\text { AGTCAG } \\
\text { TCAG }\end{array}$ & $\mathrm{CC}$ & $\begin{array}{l}\text { GGACTACHVGG } \\
\text { GTWTCTAAT }\end{array}$ & $\begin{array}{l}\text { AATGATACGGCGACCACCGAGATCTACACTGACTGCTAGTCA } \\
\text { GTCAGCCGGACTACHVGGGTWTCTAAT }\end{array}$ \\
\hline $\begin{array}{l}16 \mathrm{~S} 806 \\
R \mathrm{bc} 23\end{array}$ & $\begin{array}{l}\text { AATGATACGGCGACCAC } \\
\text { CGAGATCTACAC }\end{array}$ & $\begin{array}{l}\text { TGGCG } \\
\text { ATT }\end{array}$ & $\begin{array}{l}\text { AGTCAG } \\
\text { TCAG }\end{array}$ & $\mathrm{CC}$ & $\begin{array}{l}\text { GGACTACHVGG } \\
\text { GTWTCTAAT }\end{array}$ & $\begin{array}{l}\text { CTACACTGGCGATTAGTC } \\
\text { ГCTAAT }\end{array}$ \\
\hline $\begin{array}{l}16 \mathrm{~S} 806 \\
R \mathrm{bc} 24\end{array}$ & $\begin{array}{l}\text { AATGATACGGCGACCAC } \\
\text { CGAGATCTACAC }\end{array}$ & $\begin{array}{l}\text { TTCAG } \\
\text { CGA }\end{array}$ & $\begin{array}{l}\text { AGTCAG } \\
\text { TCAG }\end{array}$ & $\mathrm{CC}$ & $\begin{array}{l}\text { GGACTACHVGG } \\
\text { GTWTCTAAT }\end{array}$ & $\begin{array}{l}\text { AATGATACGGCGACCACCGAGATCTACACTTCAGCGAAGTC } \\
\text { AGTCAGCCGGACTACHVGGGTWTCTAAT }\end{array}$ \\
\hline $\begin{array}{l}16 \mathrm{~S} 806 \\
R \mathrm{bc} 25\end{array}$ & $\begin{array}{l}\text { AATGATACGGCGACCAC } \\
\text { CGAGATCTACAC }\end{array}$ & $\begin{array}{l}\text { TTGGC } \\
\text { TAT }\end{array}$ & $\begin{array}{l}\text { AGTCAG } \\
\text { TCAG }\end{array}$ & $\mathrm{C}$ & $\begin{array}{l}\text { GGACTACHVGG } \\
\text { GTWTCTAAT }\end{array}$ & $\begin{array}{l}\text { AATGATACGGCGACCACCGAGATCTACACTTGGCTATAGTCA } \\
\text { GTCAGCCGGACTACHVGGGTWTCTAAT }\end{array}$ \\
\hline
\end{tabular}




\section{Table 8 (on next page)}

KEGG Pathways with significant differences between meal categories as predicted by PICRUSt

PICRUSt was used to predict the functional potential of the microbial community found in each meal. This table contains all of the predicted KEGG pathways (at the 3rd hierarchical level) that vary significantly ( $p$-value $<0.05$ ) across nutrient composition or meal category type. 


\begin{tabular}{|c|c|c|c|}
\hline Nutrient/Descriptor & KEGG functional category (level 3) & $\begin{array}{l}\text { Type of test } \\
\text { used }\end{array}$ & p-value \\
\hline Calcium_bin & Peptidases & ANOVA & 0.039 \\
\hline Carotene_beta_bin & Prenytransferases & Welch's T-test & 0.041 \\
\hline Carotene_beta_bin & Vibrio cholera pathogenic cycle & 0.041 & 0.042 \\
\hline Dairy & Other glycan degradation & Welch's T-test & 0.041 \\
\hline Protein & Phenypropanoid biosynthesis & ANOVA & 0.021 \\
\hline Vitamin_C_bin & Calcium signaling pathway & ANOVA & 0.023 \\
\hline Vitamin_C_bin & Transporters & ANOVA & 0.049 \\
\hline Vitamin_A & Cytoskeleton proteins & ANOVA & 0.017451421 \\
\hline Vitamin_A & Peptidases & ANOVA & 0.019130989 \\
\hline Vitamin_A & Flavonoid biosynthesis & ANOVA & 0.023972731 \\
\hline Vitamin_A & Germination & ANOVA & 0.029007085 \\
\hline Vitamin_A & Chaperones and folding catalysts & ANOVA & 0.031168211 \\
\hline Total/lipid/bin & Secondary bile acid biosynthesis & ANOVA & 0.029181829 \\
\hline Total/lipid/bin & $\begin{array}{l}\text { Biosynthesis of siderophore group nonribosomal } \\
\text { peptides }\end{array}$ & ANOVA & 0.043392615 \\
\hline Sodium & Peptidases & ANOVA & 0.014721635 \\
\hline Sodium & Benzoate degradation & ANOVA & 0.019865137 \\
\hline Sodium & Limonene and pinene degradation & ANOVA & 0.031164989 \\
\hline Sodium & Butanoate metabolism & ANOVA & 0.032537666 \\
\hline Sodium & Nucleotide excision repair & ANOVA & 0.033766923 \\
\hline Sodium & Phenylalanine, tyrosine and tryptophan biosynthesis & ANOVA & 0.036768304 \\
\hline Sodium & Peroxisome & ANOVA & 0.037176174 \\
\hline Sodium & Ethylbenzene degradation & ANOVA & 0.039923012 \\
\hline Sodium & Naphthalene degradation & ANOVA & 0.040749468 \\
\hline Sodium & Restriction enzyme & ANOVA & 0.043486893 \\
\hline Sodium & Tyrosine metabolism & ANOVA & 0.047200716 \\
\hline Iron_bin & Carbon fixation in photosynthetic organisms & ANOVA & 0.021668245 \\
\hline Iron_bin & Protein kinases & ANOVA & 0.022263474 \\
\hline Iron_bin & Translation proteins & ANOVA & 0.024669694 \\
\hline Iron_bin & Pyruvate metabolism & ANOVA & 0.032434551 \\
\hline Iron_bin & Thiamine metabolism & ANOVA & 0.038685974 \\
\hline Iron_bin & D-Glutamine and D-glutamate metabolism & ANOVA & 0.041514757 \\
\hline Iron_bin & One carbon pool by folate & ANOVA & 0.042928705 \\
\hline Fiber_bin & Other glycan degradation & ANOVA & 0.014660951 \\
\hline Fiber_bin & N-Glycan biosynthesis & ANOVA & 0.042139092 \\
\hline Fiber_bin & Proteasome & ANOVA & 0.047590993 \\
\hline Fiber_bin & Prostate cancer & ANOVA & 0.048468144 \\
\hline Fiber_bin & Antigen processing and presentation & ANOVA & 0.048618504 \\
\hline
\end{tabular}




\section{Nutrient/Descriptor}

KEGG functional category (level 3)

Fiber_bin

Fiber_bin

Fermented

Fermented

Fermented

Fermented

Fermented

Fermented

Fermented

Fermented

Fermented

Fermented

Fermented

Fermented

Fermented

Fermented

Fermented

Fermented

Fermented

Fermented

Fermented

Fermented

Fermented

Fermented

Fermented

Fatty_acids_bin

Fatty_acids_bin

Fatty_acids_bin

Fatty_acids_bin

Fatty_acids_bin

Fatty_acids_bin

Fatty_acids_bin

Fatty_acids_bin

Fatty_acids_bin

Fatty_acids_bin

Fatty_acids_bin

Fatty_acids_bin

Fatty_acids_bin
Progesterone-mediated oocyte maturation

Other transporters

Transcription factors

Phosphonate and phosphinate metabolism

Cytoskeleton proteins

Amoebiasis

Oxidative phosphorylation

Transporters

Protein processing in endoplasmic reticulum

Riboflavin metabolism

Steroid hormone biosynthesis

PPAR signaling pathway

Peroxisome

Citrate cycle (TCA cycle)

Toluene degradation

Carbon fixation pathways in prokaryotes

alpha-Linolenic acid metabolism

Methane metabolism

Synthesis and degradation of ketone bodies

RNA degradation

Dioxin degradation

Adipocytokine signaling pathway

Benzoate degradation

Chlorocyclohexane and chlorobenzene degradation

Nicotinate and nicotinamide metabolism

Other glycan degradation

$\mathrm{N}$-Glycan biosynthesis

Proteasome

Prostate cancer

Antigen processing and presentation

Progesterone-mediated oocyte maturation

NOD-like receptor signaling pathway

Chloroalkane and chloroalkene degradation

Taurine and hypotaurine metabolism

Sphingolipid metabolism

Other transporters

Primary bile acid biosynthesis

Stilbenoid, diarylheptanoid and gingerol

\begin{tabular}{|c|c|}
\hline $\begin{array}{c}\text { Type of test } \\
\text { used }\end{array}$ & p-value \\
\hline ANOVA & 0.048618504 \\
\hline ANOVA & 0.049130295 \\
\hline Welch's T-test & 0.009468352 \\
\hline Welch's T-test & 0.011059743 \\
\hline Welch's T-test & 0.011669915 \\
\hline Welch's T-test & 0.012857954 \\
\hline Welch's T-test & 0.013841012 \\
\hline Welch's T-test & 0.015647729 \\
\hline Welch's T-test & 0.017210951 \\
\hline Welch's T-test & 0.017938599 \\
\hline Welch's T-test & 0.020976432 \\
\hline Welch's T-test & 0.021710104 \\
\hline Welch's T-test & 0.02186366 \\
\hline Welch's T-test & 0.021867149 \\
\hline Welch's T-test & 0.022788506 \\
\hline Welch's T-test & 0.024411154 \\
\hline Welch's T-test & 0.026939926 \\
\hline Welch's T-test & 0.030552388 \\
\hline Welch's T-test & 0.031611873 \\
\hline Welch's T-test & 0.032553878 \\
\hline Welch's T-test & 0.036756638 \\
\hline Welch's T-test & 0.04018659 \\
\hline Welch's T-test & 0.040925365 \\
\hline Welch's T-test & 0.04187257 \\
\hline Welch's T-test & 0.049217654 \\
\hline ANOVA & 0.002774493 \\
\hline ANOVA & 0.009783852 \\
\hline ANOVA & 0.012010853 \\
\hline ANOVA & 0.014268966 \\
\hline ANOVA & 0.014432811 \\
\hline ANOVA & 0.014432811 \\
\hline ANOVA & 0.019075184 \\
\hline ANOVA & 0.02167892 \\
\hline ANOVA & 0.022063389 \\
\hline ANOVA & 0.028794158 \\
\hline ANOVA & 0.033398699 \\
\hline ANOVA & 0.033705405 \\
\hline INOVA & 0.034295974 \\
\hline
\end{tabular}




\begin{tabular}{|c|c|c|c|}
\hline Nutrient/Descriptor & KEGG functional category (level 3) & $\begin{array}{l}\text { Type of test } \\
\text { used }\end{array}$ & p-value \\
\hline & biosynthesis & & \\
\hline Fatty_acids_bin & Glycolysis / Gluconeogenesis & ANOVA & 0.041601128 \\
\hline Fatty_acids_bin & Amyotrophic lateral sclerosis (ALS) & ANOVA & 0.045157824 \\
\hline Fatty_acids_bin & Purine metabolism & ANOVA & 0.048100832 \\
\hline Energy_bin & Nucleotide excision repair & ANOVA & 0.002532996 \\
\hline Energy_bin & Chromosome & ANOVA & 0.003249937 \\
\hline Energy_bin & $\begin{array}{l}\text { Ubiquinone and other terpenoid-quinone } \\
\text { biosynthesis }\end{array}$ & ANOVA & 0.00500867 \\
\hline Energy_bin & Mismatch repair & ANOVA & 0.006531889 \\
\hline Energy_bin & Photosynthesis proteins & ANOVA & 0.00816459 \\
\hline Energy_bin & Photosynthesis & ANOVA & 0.009638124 \\
\hline Energy_bin & Restriction enzyme & ANOVA & 0.009805668 \\
\hline Energy_bin & Carbohydrate metabolism & ANOVA & 0.009966615 \\
\hline Energy_bin & Limonene and pinene degradation & ANOVA & 0.010243464 \\
\hline Energy_bin & DNA replication proteins & ANOVA & 0.010451223 \\
\hline Energy_bin & Lipoic acid metabolism & ANOVA & 0.010843214 \\
\hline Energy_bin & Phenylalanine, tyrosine and tryptophan biosynthesis & ANOVA & 0.011059994 \\
\hline Energy_bin & Peptidases & ANOVA & 0.01407109 \\
\hline Energy_bin & DNA repair and recombination proteins & ANOVA & 0.015827001 \\
\hline Energy_bin & Type II diabetes mellitus & ANOVA & 0.016276453 \\
\hline Energy_bin & alpha-Linolenic acid metabolism & ANOVA & 0.018912274 \\
\hline Energy_bin & Butanoate metabolism & ANOVA & 0.020566276 \\
\hline Energy_bin & Homologous recombination & ANOVA & 0.025440256 \\
\hline Energy_bin & Flavone and flavonol biosynthesis & ANOVA & 0.025662772 \\
\hline Energy_bin & Protein export & ANOVA & 0.025889019 \\
\hline Energy_bin & DNA replication & ANOVA & 0.026934029 \\
\hline Energy_bin & Primary immunodeficiency & ANOVA & 0.027524778 \\
\hline Energy_bin & $\begin{array}{l}\text { Glycosphingolipid biosynthesis - lacto and neolacto } \\
\text { series }\end{array}$ & ANOVA & 0.027782212 \\
\hline Energy_bin & Indole alkaloid biosynthesis & ANOVA & 0.028725346 \\
\hline Energy_bin & Amoebiasis & ANOVA & 0.028866801 \\
\hline Energy_bin & Benzoate degradation & ANOVA & 0.029913338 \\
\hline Energy_bin & D-Alanine metabolism & ANOVA & 0.029961727 \\
\hline Energy_bin & C5-Branched dibasic acid metabolism & ANOVA & 0.030293739 \\
\hline Energy_bin & Peptidoglycan biosynthesis & ANOVA & 0.031023499 \\
\hline Energy_bin & Glycerolipid metabolism & ANOVA & 0.032020201 \\
\hline Energy_bin & Bisphenol degradation & ANOVA & 0.032129248 \\
\hline Energy_bin & Betalain biosynthesis & ANOVA & 0.032513208 \\
\hline Energy_bin & Biosynthesis of siderophore group nonribosomal & ANOVA & 0.033939326 \\
\hline
\end{tabular}




\begin{tabular}{|c|c|}
\hline Nutrient/Descriptor & KEGG functional category (level 3) \\
\hline & peptides \\
\hline Energy_bin & Melanogenesis \\
\hline Energy_bin & Amino acid metabolism \\
\hline Energy_bin & Ribosome Biogenesis \\
\hline Energy_bin & Peroxisome \\
\hline Energy_bin & Steroid hormone biosynthesis \\
\hline Energy_bin & Amino sugar and nucleotide sugar metabolism \\
\hline Energy_bin & Phosphotransferase system (PTS) \\
\hline Energy_bin & Arginine and proline metabolism \\
\hline Energy_bin & Glycine, serine and threonine metabolism \\
\hline Energy_bin & Riboflavin metabolism \\
\hline Energy_bin & Metabolism of cofactors and vitamins \\
\hline Energy_bin & Systemic lupus erythematosus \\
\hline Energy_bin & Biosynthesis of type II polyketide products \\
\hline DietType & Other glycan degradation \\
\hline DietType & N-Glycan biosynthesis \\
\hline DietType & Proteasome \\
\hline DietType & Prostate cancer \\
\hline DietType & Antigen processing and presentation \\
\hline DietType & Progesterone-mediated oocyte maturation \\
\hline Cooked & mRNA surveillance pathway \\
\hline Cooked & Cell cycle \\
\hline Cooked & Hepatitis C \\
\hline Cooked & Measles \\
\hline Cooked & mTOR signaling pathway \\
\hline Cooked & Phagosome \\
\hline Cooked & Transcription machinery \\
\hline Cooked & Various types of $\mathrm{N}$-glycan biosynthesis \\
\hline Cooked & Sporulation \\
\hline Cooked & Vibrio cholerae infection \\
\hline Cooked & Cytoskeleton proteins \\
\hline Cooked & Cytochrome P450 \\
\hline Cholesterol_bin & Transcription machinery \\
\hline Cholesterol_bin & Plant-pathogen interaction \\
\hline Cholesterol_bin & Folate biosynthesis \\
\hline Cholesterol_bin & Tetracycline biosynthesis \\
\hline Cholesterol_bin & Other ion-coupled transporters \\
\hline Cholesterol_bin & Proteasome \\
\hline
\end{tabular}

\section{Type of test used}

p-value

\begin{tabular}{|c|c|}
\hline ANOVA & 0.035235651 \\
\hline ANOVA & 0.037736626 \\
\hline ANOVA & 0.039545196 \\
\hline ANOVA & 0.040442991 \\
\hline ANOVA & 0.041078867 \\
\hline ANOVA & 0.042902641 \\
\hline ANOVA & 0.043431781 \\
\hline ANOVA & 0.043807314 \\
\hline ANOVA & 0.044386803 \\
\hline ANOVA & 0.044908782 \\
\hline ANOVA & 0.04499208 \\
\hline ANOVA & 0.045791434 \\
\hline ANOVA & 0.047100884 \\
\hline ANOVA & 0.007486572 \\
\hline ANOVA & 0.03160732 \\
\hline ANOVA & 0.034750295 \\
\hline ANOVA & 0.03926696 \\
\hline ANOVA & 0.039372465 \\
\hline ANOVA & 0.039372465 \\
\hline Welch's T-test & 0.006445676 \\
\hline Welch's T-test & 0.009317081 \\
\hline Welch's T-test & 0.009317081 \\
\hline Welch's T-test & 0.009317081 \\
\hline Welch's T-test & 0.009317081 \\
\hline Welch's T-test & 0.009317081 \\
\hline Welch's T-test & 0.021347218 \\
\hline Welch's T-test & 0.023199289 \\
\hline Welch's T-test & 0.024693602 \\
\hline Welch's T-test & 0.025037566 \\
\hline Welch's T-test & 0.04573813 \\
\hline Welch's T-test & 0.049095188 \\
\hline ANOVA & 0.007389033 \\
\hline ANOVA & 0.010583548 \\
\hline ANOVA & 0.012498951 \\
\hline ANOVA & 0.034405715 \\
\hline ANOVA & 0.036332221 \\
\hline ANOVA & 0.03995468 \\
\hline
\end{tabular}




\begin{tabular}{ll}
$\begin{array}{l}\text { Nutrient/Descriptor } \\
\text { Cholesterol_bin }\end{array}$ & \multicolumn{1}{c}{ KEGG functional category (level 3) } \\
Cholesterol_bin & General function prediction only \\
Cholesterol_bin & Prostate cancer \\
Cholesterol_bin & Antigen processing and presentation \\
Cholesterol_bin & Progesterone-mediated oocyte maturation \\
Cholesterol_bin & NOD-like receptor signaling pathway
\end{tabular}

$\begin{array}{lc}\begin{array}{c}\text { Type of test } \\ \text { used }\end{array} & \text { p-value } \\ \text { ANOVA } & 0.040216227 \\ \text { ANOVA } & 0.042978367 \\ \text { ANOVA } & 0.044525651 \\ \text { ANOVA } & 0.044753096 \\ \text { ANOVA } & 0.044753096 \\ \text { ANOVA } & 0.047390633\end{array}$

